\title{
Market Structure and Exchange Rate Pass-Through
}

\author{
Raphael A. Auer and Raphael S. Schoenle

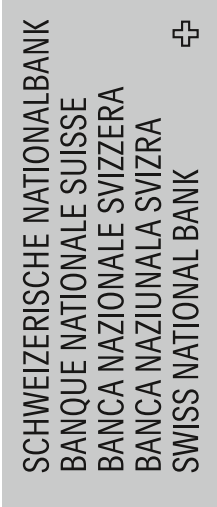

U

(4)

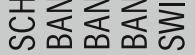


The views expressed in this paper are those of the author(s) and do not necessarily represent those of the Swiss National Bank. Working Papers describe research in progress. Their aim is to elicit comments and to further debate.

\section{Copyright $\odot$}

The Swiss National Bank (SNB) respects all third-party rights, in particular rights relating to works protected by copyright (information or data, wordings and depictions, to the extent that these are of an individual character). SNB publications containing a reference to a copyright ( $\odot$ Swiss National Bank/SNB, Zurich/year, or similar) may, under copyright law, only be used (reproduced, used via the internet, etc.) for non-commercial purposes and provided that the source is mentioned. Their use for commercial purposes is only permitted with the prior express consent of the SNB.

General information and data published without reference to a copyright may be used without mentioning the source.

To the extent that the information and data clearly derive from outside sources, the users of such information and data are obliged to respect any existing copyrights and to obtain the right of use from the relevant outside source themselves.

\section{Limitation of liability}

The SNB accepts no responsibility for any information it provides. Under no circumstances will it accept any liability for losses or damage which may result from the use of such information. This limitation of liability applies, in particular, to the topicality, accuracy, validity and availability of the information.

ISSN 1660-7716 (printed version)

ISSN 1660-7724 (online version)

๑ 2012 by Swiss National Bank, Börsenstrasse 15, P.0. Box, CH-8022 Zurich 


\title{
Market Structure and Exchange Rate Pass-Through*
}

\author{
Raphael A. Auer and Raphael S. Schoenle ${ }^{\dagger}$ \\ Swiss National Bank and Brandeis University
}

August 30, 2012

\begin{abstract}
In this paper, we examine the extent to which market structure and the way in which it affects pricing decisions of profit-maximizing firms can explain incomplete exchange rate passthrough. To this purpose, we evaluate how pass-through rates vary across trade partners and sectors depending on the mass and size distribution of firms affected by a particular exchange rate shock. In the first step of our analysis, we decompose bilateral exchange rate movements into broad US Dollar (USD) movements and trade-partner currency (TPC) movements. Using micro data on US import prices, we show that the pass-through rate following USD movements is up to four times as large as the pass-through rate following TPC movements and that the rate of pass-through following TPC movements is increasing in the trade partner's sector-specific market share. In the second step, we draw on the parsimonious model of oligopoly pricing featuring variable markups of Dornbusch (1987) and Atkeson and Burstein (2008) to show how the distribution of firms' market shares and origins within a sector affects the trade-partner specific pass-through rate. Third, we calibrate this model using our exchange rate decomposition and information on the origin of firms and their market shares. We find that the calibrated model can explain a substantial part of the variation in import price changes and pass-through rates across sectors, trade partners, and sector-trade partner pairs.
\end{abstract}

JEL Classification: E3, E31, F41

Keywords: Exchange Rate Pass-Through, U.S. Import Prices, Market Structure, Price Complementarities.

${ }^{*}$ This research was conducted with restricted access to the Bureau of Labor Statistics (BLS) data. The views expressed here are those of the authors and do not necessarily reflect the views of the BLS or the Swiss National Bank. We thank project coordinators Kristen Reed and Rozi Ulics for their substantial help and effort and Rawley Heimer and Miao Ouyang for excellent research assistance. We also thank Gita Gopinath, Anthony Landry, and Romain Ranciere, as well as participants at the Milton Friedman Institute Conference on Pricing at the University of Chicago, the University of Geneva, the University of Berne, the University of Munich, the Microeconomic Aspects of the Globalization of Inflation Conference at the Swiss National Bank, the 2011 Midwest Macro Meetings at Vanderbilt University, the 2011 European Economic Association Meetings at the University of Oslo, the 2012 meetings of the Austrian Economic Association at the Technical University of Vienna, the 2012 meetings of the Society for Economic Dynamics in Limmasol, the 2012 CEPR Summer Symposium in International Macroeconomics in Tarragona, the 2012 NBER Summer International Finance and Macroeconomics workshop and in particular an anonymous referee at the SNB Working Paper series for helpful comments and suggestions.

${ }^{\dagger}$ Contact: Raphael Auer, Swiss National Bank, Börsenstr. 15 P.O. Box Ch-8022 Zürich Switzerland. Phone: +41 4463138 84, e-mail: raphael.auer@snb.ch. Raphael Schoenle, Mail Stop 021, Brandeis University, P.O. Box 9110, 415 South Street, Waltham, MA 02454. Phone: +1-617-680-0114, email: schoenle@brandeis.edu. 


\section{Introduction}

Studying firms' pricing-to-market decisions is one of the important research topics in international macroeconomics because it relates to the movement of international relative prices, expenditure switching and the adjustment of global imbalances, and imported inflation. Moreover, this line of research can also inform us about the nature of price-setting, which features prominently in most macro-economic models.

The recent empirical literature estimating exchange rate pass-through at the good level has yielded important insights into firms' pricing behavior following exchange rate shocks. ${ }^{1}$ While the results have uncovered much heterogeneity along multiple dimensions of firm or good characteristics, ${ }^{2}$ a common finding is that pass-through, even when estimated at the dock and over long horizons, is quite incomplete: import prices do not move one-to-one with the exchange rate.

Incomplete long-run pass-through can be explained by markups being adjusted to accommodate the local market environment, a channel first pointed out in Krugman (1986) and Dornbusch (1987) and more recently in Melitz and Ottaviano (2008), Atkeson and Burstein (2008), Chen et al. (2009), Gust et al. (2009, 2010), and Gopinath and Itskhoki (2011).

In this paper, we contribute to this literature by identifying how exchange rate shocks affect the market environment differently in different sectors depending on the mass and size distribution of firms that is affected by a particular exchange rate shock. Because we focus on the variation in pass-through rates across both sectors and trade partners, we are able to discern the role of market structure from alternative explanations, that is, from the view that costs simply do not move one-to-one with the exchange rate.

Our analysis proceeds in three steps. In the first step of our analysis, we document several salient facts showing that pass-through rates vary across trade partners and sectors depending on mass of firms affected by a particular exchange rate shock.

\footnotetext{
${ }^{1}$ While some of these studies focus on structural analysis of exchange rate pass-through in single industries (see Knetter (1989) and Knetter (1992) and the analysis of pricing-to-market practices in Verboven (1996), Goldberg and Verboven $(2001,2005)$ for the car industry, Hellerstein (2008) for the beer industry, and Nakamura and Zerom (2010) for the case of the coffee industry), our approach is more closely related to the reduced-form analysis of pass-through rates in datasets spanning many industries (see Gopinath and Rigobon (2008), Gopinath and Itskhoki (2010), Gopinath et al. (2010), and Nakamura and Steinsson (2008a)). It is also related to the work of Fitzgerald and Haller (2010), who use plant-level prices of identical goods sold on different markets to study pricing-to-market decisions.

${ }^{2}$ When evaluating prices at the dock (that is, net of distribution costs), the main dimensions along which the heterogeneity of pass-through rates are identified include the currency choice of invoicing as in Gopinath et al. (2010), Goldberg and Tille (2009), Bacchetta and van Wincoop (2005), inter- versus intra-firm trade as in Neiman (2010), multi-product exporters as in Chatterjee et al. (2011), sectoral import composition as in Campa and Goldberg (2005); Goldberg and Campa (2010), and input use intensity. When evaluating retail prices, the share of the distribution costs may matter for pass-through as found by Bacchetta and van Wincoop (2003) and Burstein et al. (2003), while the movement of margins seems to play only a minor role as shown in Goldberg and Hellerstein (2012). Generally, also the size and origin of the exchange rate movement matter for pass-through (see Michael et al. (1997) and Burstein et al. $(2005,2007)$ ) as does the general equilibrium interaction between exchange rate volatility, invoicing currency choice, and pass-through rate (see Devereux et al. (2004)).
} 
To document these salient facts, we first show that exchange rate movements are passed through into US import prices significantly differently when the bilateral exchange rate change is driven specifically by the trade partner currency as opposed to when it is reflecting a broad movement of the USD against all trade partners. To this purpose, we decompose bilateral exchange rate movements into broad USD movements common to all importers and into trade-partner currency (TPC) specific movements. We then estimate pass-through following these two different shocks using micro data on US import prices. We find that pass-through at horizons up to two years is equal to up to $31 \%$ following a USD movement, but only up to $8 \%$ following a TPC movement.

The next salient fact we document is that pass-through rates vary with the mass of firms that is affected by the TPC exchange rate shock. For TPC movements, we find that the rate of passthrough is increasing in the trade partner's sector-specific import share. We find the importance of sector-specific market share to be economically very large. Over longer horizons, the rate of passthrough of a hypothetical US trade partner with an import share near zero equals around 10\%, while the pass-through rate is nearly four times as large for a hypothetical trade partner with a market share of $100 \%$. Nearly one third of the aggregate two-year pass-through rate in our sample, equal to $16 \%$, is explained by the fact that trade partner market shares are non-negligible.

We view these patterns in the data as a strong indicator that the rate of pass-through is highly dependent on the way in which an exchange rate shock and a sector's market structure interact to shape firms' equilibrium price responses to exchange rate movements. However, these reducedform estimations are limited in nature because they only capture a very coarse element of market structure, namely the combined market share of firms affected by a specific exchange rate shock. Heterogeneous firms of different size potentially react differently to the same exchange rate shock, so that the entire size distribution of firms should matter for pass-through. Indeed, Berman et al. (2012) find that pass-through varies substantially according to firm size. ${ }^{3}$ Thus, differences in the distribution of firm sizes across sectors, trade partners, and trade partner-sector pairs are potentially also important in explaining pass-through.

In the second step of our analysis, we therefore use the additional structure from a parsimonious model of oligopoly pricing, following Dornbusch (1987) and Atkeson and Burstein (2008), to include information on the entire size and origin distribution of firms into our estimation. We first document how oligopoly-pricing in the preference setup of Dornbusch (1987) and Atkeson and Burstein (2008) determines pass-through rates, identifying two elements how a sector's market structure affects the pass-through rate. The first element is that the rate at which a firm reacts to changes in the exchange rate depends on its market share. The average direct price response of the set of firms affected by a given exchange rate shock thus depends on the distribution of their market shares. The

\footnotetext{
${ }^{3}$ Relatedly, Manova and Zhang (2012) show that export pricing patterns are related to firm characteristics, while Feenstra (1994), Andrade et al. (2012) and Garetto (2012) document how pricing-to-market decisions are affected by firm market share. Auer et al. (2012), who as Garetto (2012) use the dataset of car prices sold on five European markets Goldberg and Verboven (2001, 2005), document how the quality of the produced good affects pricing-tomarket and exchange rate pass through.
} 
second element is that the price changes of firms from a trade partner affect the industry's general price level and thus the pricing decisions of all firms in the industry. The first-round impact on the general price level is proportional to the combined market share of firms from the trade partner. Moreover, there is a further amplification of the price shock since all other firms in the industry react to the changing general price level, multiplying the initial impact. In this sense, pass-through is affected by the sector's entire market structure also if only few firms are affected by a given exchange rate movement.

In the third step of this analysis, we map the developed theoretical pricing framework back to the BLS micro data. We then test it in two ways: first, we test whether this preference setup can match actual price changes and second, if it can explain the heterogeneity of pass-through rates across trade partners when it is calibrated using the TPC movements on the one hand and information on a sector's market structure one the other hand.

We find strong evidence for the predictions of the model relating market structure and passthrough when we estimate it using the TPC movements and information on the market structure of the entire sector. ${ }^{4}$ The model is able to explain both qualitatively and quantitatively the size of price changes, as well as a substantial part of the variation in pass-through across sectors and trade partners.

We undertake two sets of exercises. In the first set, we show that the model can explain actual price changes in the BLS micro data when we relate model-predicted to actually observed price changes at the firm level. For this set of tests, we construct predictions of firm-specific price changes using the theoretical pass-through predictions and our exchange rate decomposition. We then relate the predicted to the actually observed price changes, which serves mostly to establish how simulation assumptions, sample restrictions, and addition of relevant fixed effects impact our results.

We document the explanatory power of the TPC price change predictions under alternative assumptions and then document the explanatory power of our predictions following both TPC and USD movements. In a further robustness analysis, we examine the details of mapping our theory to the BLS data, show the variation in the data that is behind our results by including various fixed effects, and exclude subgroups of countries. For this set of exercises, we document both the average response of actual to predicted prices and also, the relation between these actual and, following Gopinath and Rigobon (2008) to address nominal price rigidities, predicted prices conditional on a non-zero price change.

These empirical exercises provide strong evidence for the predictive power of the DornbuschAtkeson-Burstein setup in explaining firms' pricing responses to exchange rate movements: not only

\footnotetext{
${ }^{4}$ This exercise is related to Pennings (2012), who undertakes a similar calibration to evaluate the cross-currency rate of pass-through, that is, the effect of the USD/Euro exchange rate on the prices that Japanese firms charge in the US. Gopinath and Itskhoki (2011) directly estimate the importance of such complementarities using the average change of competitor's prices. Bergin and Feenstra (2009) also study such cross-currency price effects.
} 
do predicted price changes correlate significantly with actual price changes both conditionally and unconditionally, but the coefficients of the conditional estimates are closer to 1 and in not few cases statistically indiscernible from 1 , that is, our point estimates are also quantitatively good predictors of actual price changes. Overall, in terms of $R^{2}$, we can explain up to $19 \%$ of the non-zero price changes in the differentiated goods subsample with the USD and TPC induced price changes. We also show that our setup matches the overall distribution of price changes better than a benchmark constant-markup model.

In the second set of the emprical exercises, we aggregate our predictions up to the industrycountry level and show that our theory is economically highly significant in explaining pricing behavior at these important aggregate levels. ${ }^{5}$ Our predicted price changes correlate with actual ones at very high levels of significance and they often do so at a rate that is statistically not different from 1 , that is we do not only qualitatively explain pass-through rates, but also quantitatively. When evaluating differences in pass-through rates, we document that a substantial part of the variation in pass-through across sectors and trade partners - approximately a third - can be explained by differences in the mass and size distribution of firms across the trade partners.

Overall, we draw three conclusions from our theoretical and empirical analysis: First, we conclude that the effect of the exchange rate on the competitive environment and, in turn, on equilibrium markups is substantial. This highlights the importance of including price complementarities in macroeconomic models, may these complementarities arise from strategic motives as in Kimball (1995) and Dotsey and King (2005) or from the shape of the utility function as in Gust et al. (2010) and Chen et al. (2009). This conclusion has also important modeling implications for firms' pricing decisions in the domestic economy: if the optimal price of a firm reacts strongly to a cost shock, already small menu costs can substantially reduce the frequency of price changes (see, for example, Bils and Klenow (2004) and Nakamura and Steinsson (2008b) for evidence on how frequently domestic firms change prices).

Second, we conclude that the Dornbusch-Atkeson-Burstein style departure from the case of constantly elastic demand greatly improves our understanding of pass-through rates in the data. As Atkeson and Burstein (2008), we do not view the proposed model as a general model of pricingto-market, but rather as the simplest possible departure from the case of constant elasticity demand. Demonstrating how far the calibrated model is from the data can inform us whether more complex theories of pricing to market are necessary to reconcile theory and data. From an empiricist's point of view, our results suggest that knowing the distribution of firm's market shares is sufficient to calculate aggregate pass-through rates.

Third, from a policy maker's perspective, our findings are relevant given the economic magnitude

\footnotetext{
${ }^{5}$ In this set of exercises, the sample is much smaller than in the first set, as we need a large number of observations to estimate one pass-through rate. However, the second set focuses on the economic significance: we can analyze how much of the empirically observed variation in pass-through rates across sectors, trade partners and sector-trade partners can be explained with differences in market structure.
} 
of the uncovered relations. The finding that pass-through following broad USD movements is very large gives rise to a much bigger role for the exchange rate on inflation dynamics - especially in times of large, permanent exchange rate evaluations - than is commonly assumed: the passthrough response by individual firms is exactly then the largest when all exchange rates move in the same direction vis-a-vis the dollar. ${ }^{6}$ Additionally, our findings reveal that the aggregate rate of pass-through is large when the trade partner is either large or concentrated in specific sectors.

The structure of this paper is the following. We describe our exchange rate decomposition and the resulting reduced-form pass-through estimations in Section 2. Section 2.3 examines whether pass-through depends on trade partner market shares and the trade openness of U.S. sectors. Section 3 presents the model, highlighting the role of firm- and trade partner- market shares for pass-through, and Section 4 examines whether a calibrated version of the model can explain import price adjustments and pass-through rates. Section 5 documents to what extent the model can explain differences in aggregate pass-through rates. Section 6 concludes.

\section{How are General and Trade-Partner Specific Exchange Rate Movements Passed Through Into US Import Prices?}

In this section, we discuss how we decompose changes in the nominal bilateral exchange rate into broad USD movements on the one hand and trade-partner specific movements on the other hand. Then, we show that pass-through is systematically different when the USD moves against all of its trade partners rather than when the change in the bilateral nominal exchange rate is caused by a trade partner movement against the rest of the world. A description of the data we use can be found in Appendix B.

This exercise is motivated by theoretical considerations relating pass-through to how the market environment changes with the exchange rate. For example, if we think along the lines of Atkeson and Burstein (2008), where market power determines pass-through, pass-through should be very different if all foreign firms face the same cost shock as opposed to when only a small set of firms from a country such as Switzerland faces a cost shock. Theoretical models that highlight nonstrategic price complementarities such as Chen et al. (2009) or Gust et al. (2009) also predict that pass-through should be higher when the USD appreciates against all countries since all exporters experience the same cost shock in that case.

\subsection{USD and Trade-Partner Currency Movements}

Building on Glick and Rogoff (1995) and Gopinath and Itskhoki (2011), we decompose the bilateral exchange rate into idiosyncratic TPC movements and broad USD movements. First, we define

\footnotetext{
${ }^{6}$ Such large import price movements, in turn, might also affect the prices domestic firms charge (a channel analyzed in Auer (2012)).
} 
the USD/ROW exchange rate change for a specific trade partner as the import-weighted average change of the log bilateral USD exchange rate against all countries except for the trade partner under consideration. That is, if $T P$ indexes the trade partner, the change of the USD exchange rate against the rest of the world (ROW) except $T P$ equals

$$
\Delta U S D_{R O W-T P, t} \equiv \sum_{c \in(C \supset\{T P, U S A\})} \omega_{c, t} \Delta e_{c, t}
$$

where $\Delta e_{c, t}$ is the bilateral exchange rate between the US country $c$ and country $c$ 's weight equals its shares of US imports excluding country TP. To make sure that the weights are not contemporaneously related to current exchange rate movements, we take last year's import share as current weights:

$$
\omega_{T P, t} \equiv \frac{I M_{T P, t-1}^{U S}}{\sum_{c \neq T P, U S A} I M_{c, t-1}^{U S}} .
$$

It is important to note that the USD/ROW exchange rate change differs for each trade partner due to the inclusion of a different set of countries. Therefore, it differs from a standard trade-weighted exchange rate. We discuss this difference further below.

Second, we define the "TPC exchange rate movement against the ROW" (TPC) as the difference between the bilateral exchange rate change and the broad USD exchange rate change

$$
\Delta T P C_{T P, t} \equiv \Delta e_{c, t}-\Delta U S D_{R O W-T P, t}
$$

We note that $\triangle T P C_{T P, t}$ is equal to the negative of the average change (using US weights) of the trade partner currency against all countries other than the USA. ${ }^{7}$ This exchange rate decomposition is similar in spirit to constructing an import-weighted exchange rate index and then interpreting the residual difference of the bilateral nominal exchange rate and the import-weighted exchange rate index as an idiosyncratic trade partner currency movement.

However, our approach is different in that takes into account the effect of large trade partners on the import-weighted exchange rate index. For example, if the currency of a trade partner providing $15 \%$ of US imports appreciates by $10 \%$ against the USD, while all other exchange rates remain flat

\footnotetext{
${ }^{7}$ This can be verified by noting that for any three currencies USD, TPC, and $c$, the absence of arbitrage possibilities implies that$$
\Delta U S D_{T P, t}=\Delta U S D_{c, t}-\Delta T P C_{c, t}
$$

for any country $c$. Since the weights $\omega_{c, t}$ sum to one, it is thus true that

$$
\Delta U S D_{T P, t}=\sum_{c \epsilon(C \supset\{T P, U S A\})} \omega_{c, t}\left(\Delta U S D_{c, t}-\Delta T P C_{c, t}\right) .
$$

Noting the definition of $\triangle U S D_{R O W-T P, t}$ and $\triangle T P C_{T P, t}$ then implies

$$
\Delta T P C_{T P, t}=-\sum_{c \epsilon(C \supset\{T P, U S A\})} \omega_{c, t} \Delta T P C_{c, t} .
$$


against the USD, our decomposition will correctly measure a TPC movement of $10 \%$. In contrast, an approach based on the import-weighted exchange rate index would yield a TPC movement of $8.5 \%$ since the import-weighted exchange rate index itself moves by $10 \% * 15 \%=1.5 \%$.

Using an import-weighted exchange rate index instead of our USD measure would make it difficult to econometrically disentangle pass-through following USD movements as opposed to following TPC movements. Even worse, not controlling for the effect of large trade partners on the importweighted exchange rate index would introduce a mechanical bias in the regressions estimated in Section 2.3 below that relates import shares to the rate of TPC pass-through, as large trade partners would by construction have a lower TPC volatility. Because both US imports and the BLS import price data are dominated by large trade partners such as China, Canada, and Mexico (overall import share in 2010: $19.2 \%, 14.5 \%$, and $12.1 \%$ respectively), this problem is not trivial in the data. $^{8}$

Our decomposition is closely related to Gopinath and Itskhoki (2011), who use the residuals from a regression of the trade-weighted exchange rate on the bilateral USD exchange rate as a measure of broad USD movements; that is, they use the element of the US trade-weighted exchange rate that is orthogonal to the bilateral one. While these two approaches of defining a broad USD movement are numerically not too different, we find it conceptually easier to work with the deterministic decomposition. $^{9}$

More importantly, the main conceptual difference between Gopinath and Itskhoki (2011) and our approach is due to our focus on TPC movements: we are interested in the pass-through rate following the part of the bilateral exchange rate that is not driven by a general appreciation, that is, our TPC movements are equal to the bilateral minus the ROW exchange rate. Gopinath and Itskhoki (2011), in contrast, use the bilateral exchange rate directly and control for the ROW exchange rate. While this difference is trivial for the analysis evaluating only the aggregate passthrough rate (since the pass-through coefficients are linear transformations of each other), it matters in sections 2.3 and 4 , in which we interact TPC movements with each trade partner's market share and other sector-specific information.

\footnotetext{
${ }^{8}$ For the US, it is also common to estimate the pass-through rate of changes in the "Broad Exchange Rate" which is an rate index constructed by the Federal Reserve Board giving a $50 \%$ weight on import share, $25 \%$ on export share, and $25 \%$ on a measure of "third-market competitiveness" as described in Loretan (2005). While the broad exchange rate index may be a useful concept when evaluating the effect of the exchange rate on the current account or the macro economy in general, we consider using only import weights a more relevant statistic when estimating how the average exchange rate and average import prices comove.

${ }^{9}$ The exact difference between these two approaches is that we only net out each country's mechanical contribution to the trade-weighted exchange rate, whereas Gopinath and Itskhoki (2011) also include the covariance of the TP exchange rate with other exchange rates. For example, Iceland's import share is minuscule (around 0.0002), so that for the Icelandic kronor, the change in the ROW exchange rate we construct is nearly identical to the change in the US-trade-weighted exchange rate. However, since the kronor co-moves with other exchange rates, its regression coefficient on the US trade-weighted exchange rate is equal to 0.169. We note that despite of what this example suggests, the difference between our approach and the one in Gopinath and Itskhoki (2011) is not too sizeable. The correlation between these two variables is equal to 0.79 and a regression yields a slope of 1.023 (which is significantly different from 1).
} 


\subsection{Pass-Through Following TPC and USD Movements}

We measure pass-through by estimating a stacked regression where we regress monthly import price changes on monthly lags of the respective measure of the exchange rate. Following Gopinath and Rigobon (2008), our baseline specification is

$$
\Delta p_{i, c, t}=\alpha_{c}+\sum_{j=1}^{n} \beta_{j} \Delta e_{c, t-j+1}+\sum_{j=1}^{n} \gamma_{j}^{T P} \Delta \pi_{c, t-j+1}^{T P}+\epsilon_{i, c, t}
$$

where $i$ indexes goods, $c$ trade partners, $\alpha_{c}$ is a country fixed effect, $n$ measures the length of the estimated pass-through horizon and varies from 1 to 25 , and $\Delta e_{c, t-j}$ is the change in either the $\log$ of the nominal, USD, or TPC exchange rate. $\Delta \pi_{c, t}^{T P}$ is the monthly inflation rate in the foreign country using the consumer price index. To obtain the $n$-months pass-through rate, we sum the coefficients up to the respective horizon. Alternatively, we also estimate a joint specification:

$$
\Delta p_{i, c, t}=\alpha_{c}+\sum_{j=1}^{n} \beta_{j}^{U S D} \Delta U S D_{R O W-c, t-j+1}+\sum_{j=1}^{n} \beta_{j}^{T P C} \Delta T P C_{c, t-j+1}+\sum_{j=1}^{n} \gamma_{j} \Delta \pi_{c, t-j+1}^{T P}+\epsilon_{i, c, t}
$$

where $\triangle T P C_{c, t}$ corresponds to the TPC movement of country $c$ and $\Delta U S D_{R O W-c, t}$ to the USD movements of the exchange rate for country $c$.

Figures 1 and 2 and Table C.1 in Appendix C present our results from estimating Equations (3) and (4). Column (1) in Table C.1 presents these estimates for the nominal bilateral USD exchange rate. The rows list the cumulative pass-through coefficient equal to $\sum_{j=1}^{n} \beta_{j}$ for $1,3,6,12,18$, and 24 month(s) and the corresponding standard error. All summed coefficients are significant at the $1 \%$ level. Columns (2) and (3) then repeat this specification using the USD-movement and the TPC movement respectively.

When we estimate pass-through for each component of the exchange rate, we find that USD movements are passed through at more than twice the rate of nominal movements. For example, at the six-month horizon, USD pass-through is estimated at $31 \%$, while nominal exchange-rate pass-through is estimated at only $11 \%$ (see third row and columns (1) and (2), respectively). At the two-year horizon, USD pass-through is at $32 \%$ while the rate of pass-through conventionally estimated is at $15 \%$. The result of high USD pass-through rate confirms the finding of higher trade weighted exchange rate pass-through of Gopinath and Itskhoki (2011) and also agree with them quantitatively. ${ }^{10}$

The striking novel result of our analysis comes from the estimation of TPC currency passthrough: for any horizon, TPC exchange rate pass-through is even lower than bilateral exchange

\footnotetext{
${ }^{10}$ Any residual differences between and our results and Gopinath and Itskhoki (2011) can be attributed to differences in the steps in data construction of the micro data and our exchange rate measures, which are derived as weighted sums and deviations thereof. Also, our sample selects out any time series with less than 72 months of data and drops BLS country codes below 1000 which are aggregates of more than one country.
} 
rate pass-through which is already less than USD pass-through. At the two-year horizon, TPC is only $7.34 \%$ compared to $32 \%$ USD pass-through as columns (2) and (3) show. ${ }^{11}$

Figure 1 summarizes this finding graphically, based on the separate pass-through estimations of columns (1) to (3) in Table C.1 for all lagged horizons. It shows the pass-through estimates that can be attributed to a movement of the USD against all partner currencies, a movement of the trade partner currency against the rest of the world or simply a nominal exchange rate movement. While USD pass-through is larger at all monthly horizons, it is at approximately $35 \%$ at horizons over one year. Trade-partner pass-through at that horizon is estimated at around only 5\%, while nominal exchange rate pass-through is estimated at around $10 \%$.

When we jointly estimate pass-through of our two components of the nominal exchange rate, that is, broad USD and TPC movements, we find an even stronger impact of broad USD movements on U.S. import prices. Figure 2 as well as Columns (4) and (5) in Table C.1 present the same comparison for the joint pass-through rates following USD and TPC movements, which is estimated using Equation (4). In this joint estimation, the USD pass-through rate is also estimated to be between three to over four times as large as the TPC pass-through rate. The TPC pass-through is low, topping out at $10.15 \%$ at the one-and-a-half years horizon. In this joint estimation, we can test whether USD pass-through is the same as TPC pass-through in a statistical sense, or not. They are so at the $1 \%$ significance level at all horizons except the 24 months one. This is also graphically demonstrated in Figure 2 using confidence bands.

In Appendix C, we document that the difference in pass-through rates following TPC and USD movements is not driven by specific sectors or specific countries. We present robustness checks that confirm that pass-through of broad USD movements is larger than trade-partner or bilateral exchange rate pass-through also at the country and two-digit NAICS level, that is, broad USD movements are passed through into U.S. import prices at a substantially higher rate than tradepartner movements.

Despite these results, a further important concern is that when estimating Equation (3), we are not properly controlling for changes in firms' production costs. A USD movement could be associated with a very high cost shock as it moves the world market prices for intermediate goods. Also a TPC shocks could simply reflect productivity growth in the trade partner, which would also influence the prices of importers for reasons other than the exchange rate fluctuation. ${ }^{12}$

\footnotetext{
${ }^{11}$ It is unlikely that the different PT rate following TPC and USD shocks is explained by differences in the properties of these exchange rate series. During 1994-2004 and in the group of OECD economies, the standard deviation of monthly exchange rate changes is $3 \%$ for the bilateral exchange rate, $1.3 \%$ for the USD movements, and $2.6 \%$ for the TPC movements. Persistence of these three time series is very similar: in this sample, the sum of AR coefficients up to 12 -month lagged levels of the exchange rate is equal to $0.803,0.794$, and 0.814 for the bilateral, USD movements, and TPC movements respectively.

${ }^{12}$ In a discussion of our paper, Landry (2011) re-estimates specification (3) using our exchange rate decomposition on the dataset of Baxter and Landry (2010). The latter dataset includes the prices of identical IKEA goods sold on different markets, with the advantage that one can control for changes in the cost of a good sold on other markets, yielding a much better cost control than in our specification. He finds a 2-year rate USD pass-through nearly identical to our specification. See also Baxter and Landry (2010).
} 
To address this concern, we proceed to utilizing the cross section of our dataset, that is variation in the import share of a specific country across the sectors. While the exchange rate is endogenous to average productivity growth, this gives us additional sectoral variation in the extent to which prices react to the exchange rate. We thus proceed to examine how the sectoral import share correlates with the TPC pass-through rate.

\subsection{Market Share and Pass-Through}

In this subsection, we show that TPC pass-through is increasing in the import share of the country from which the firm is exporting. This suggests that low TPC pass-through may be due to individual trade-partner on average having low market shares.

We show that the response to TPC movements is dependent on the market share of the respective importers. We define the sector-specific import share of trade partner $c$ in sector $k$ as

$$
m_{c, k}=\frac{\text { Imports }_{c, k}}{\text { World Imports }}
$$

Then, we run an augmented, reduced-form pass-through specification where we interact the sectorspecific import share of the trade partner with TPC exchange rate movements:

$$
\Delta p_{i, c, k, t}=\alpha_{c}+\sum_{j=1}^{n} \beta_{j} \Delta T P C_{c, t-j+1}+\sum_{j=1}^{n} \gamma_{j} m_{c, k} \Delta T P C_{c, t-j+1}+m_{c, k}+\epsilon_{i, c, k, t},
$$

where $i$ denotes a good, $\alpha_{c}$ is a country fixed effect, $k$ a sector, $n$ varies from 1 to 25 , and $\Delta T P C_{c, t}$ is the change in the trade-partner currency, and $m_{c, k}$ denotes the sector-specific import share measure of country $c$ in a given six-digit NAICS sector $k$ for the year 2002 .

To obtain the $n$-months direct rate of pass-through, we sum the coefficients $\beta_{j}$ up to the respective horizon. To obtain the indirect effect working through the measure of market power, we sum the coefficients $\gamma_{j}$ up to the respective horizon. When we multiply the sum of $\gamma_{j}$ with the average respective market share from the data, this yields the effective interaction with the right economic magnitude.

The three lines displayed in Figure 3 reflect the pass through rate following a TPC shock for three sectors in which firms from the trade partners make up around $0 \%$ (that is, there are some importers from the TP so that prices exist, but they are negligible in size; see solid line), $31 \%$ (which is equal to the median of $m_{c, k}$ in our data; see dotted line) and $100 \%$ (solid marked line). For each lag length $n$, the solid line corresponds to the sum of the coefficients $\sum_{j=1}^{n} \beta_{j}$ in Equation (2.3). The difference between the solid marked line and the solid line corresponds to the sum of the interaction coefficients $\sum_{j=1}^{n} \gamma_{j}$ in Equation (2.3).

We find that there is a sizeable impact of market share on the degree of exchange rate passthrough. In a sector in which a trade partner has around $0 \%$ of the import market, the TPC 
pass-through rate is around $13 \%$ at the 2 year horizon. In a sector where the trade partner supplies nearly $100 \%$ of imports, the TPC pass-through rate is equal to $38 \%$ at the same horizon, that is, it is 25 percentage points higher ( 0.25 is equal to the interaction term $\sum_{j=1}^{24} \gamma_{j}$ in the estimation of Equation (2.3)).

For a sector with median import share (the median of $m_{c, k}$ is equal to $31 \%$ ), the average longrun pass-through rate is equal to $21 \%$, of which $0.31 * 0.25=0.0775$ is attributed to the interaction term, that is, to the fact that the median sector has a nonnegligible import share. Thus, in economic terms, non-zero import shares explain more than a third of the long-run TPC pass-through rate for the typical firm.

We note that the above-described salient facts relate the total importer's market share to pass-through rate, but are mute about the relationship between firm-specific market share and pass-through. In fact, Berman et al. (2012) document that large firms change their prices less to an exchange rate movement than do small firms. The difference between Berman et al. (2012)'s findings and ours is that we here consider a country's market share, while Berman et al. (2012) consider firm-specific market shares. We connect these two insights in the next section. ${ }^{13}$

\section{Market Structure and Pass-Through: Theory}

In the preceding analysis, we have documented that there is a strong reduced-form relationship between the degree of pass-through and the combined market share of the firms that are affected by the exchange rate movement. We have suggested that the documented stylized facts are consistent with pricing theories that argue for the importance of pricing-to-market and price complementarities.

We next develop a simple model of pricing-to-market in this spirit that is based on Dornbusch (1987) and, in its log-linearized version on Atkeson and Burstein (2008) to formalize these statements and to guide our main empirical analysis. In particular, the aim of this section is to develop a framework that conceptualizes "market structure" in the context pricing-to-market decisions. While there are four commonly recognized types of market structures - perfect competition, monopolistic competition, oligopoly, and monopoly- a realistic mapping of market structure into pass-through rates requires a more gradual definition. We thus use the framework of Dornbusch (1987) and Atkeson and Burstein (2008) to guide our theoretical analysis and show how the passthrough rate depends on the number of firms that is affected by an exchange rate movement, their respective market shares, and the firm size distribution in the entire industry.

We note that many previous studies have used these preferences to analyze pricing-to-market

\footnotetext{
${ }^{13}$ The finding that the total market share of all firms originating from a specific trade partner is related to Feenstra et al. (1996), who develop a differentiated products model in which firms compete a la Bertrand to show that the relationship between the pass-through rate and the trade partner market share is non-linear. They find evidence for the theoretically predicted non-linearity when they examine the relationship between exporter market share and pass-through in the global car industry.
} 
decisions as, for example, Yang (1997). Given that it is well known from previous work that markups are variable and optimal prices respond to the prices of competitors under such preferences, we view our contribution as adapting this well-established theory to a microeconomic dataset and highlighting how market structure affects the degree of exchange rate pass-through. We first show that the reduced-form relationships that we have estimated above can indeed be rationalized as the outcome of this preference setup. Then, we explicitly discuss how other aspects of market structure influences pass-through rates.

We also note that, as Atkeson and Burstein (2008), we do not view the proposed model as a general model of pricing to market, but rather as the simplest possible departure from the case of constant elasticity demand. Demonstrating how far the calibrated model is from the data can inform us whether more complex theories of pricing to market are necessary to reconcile theory and data.

\subsection{The Dornbusch-Atkeson-Burstein Model}

Our model relies on the preferences introduced by Dornbusch (1987) in which markups are variable since a firm's market share affects the firm's elasticity of substitution. This preference setup captures two main economic forces: first, pass-through is less than one as markups adjust to a cost shock and second, not only a firm's own costs matter, but also the prices of all other firms.

The preferences are given by a two-tiered "love of variety" utility/production function setup in which consumers consume the output of sectors $k$ and the output of each sector is produced by combining varieties $n$ within each sector.

On the production side, within each sector there exist a number $N_{k}$ of individual firms each holding the monopoly to produce an input variety. All input varieties within a sector are then used as inputs by competitive firms combining these inputs into the sector composite $y_{k}$ using a production function that features a constant elasticity of substitution. On the preference side, as in Dixit and Stiglitz (1977), consumers have preferences with constant-elasticity demand for each sector's total output.

Final consumption $c$ is produced by competitive firms aggregating input goods into

$$
c=\left(\int_{0}^{1} y_{k}^{(\eta-1) / \eta} d k\right)^{\eta /(\eta-1)}
$$

Each final producer's optimization yields

$$
y_{k}=\left(\frac{P_{k}}{P}\right)^{-\eta} c
$$

where $P$ is the unit price of the final output and equal to $\left(\int_{0}^{1} P_{k}^{(1-\eta)} d k\right)^{1 /(1-\eta)}$. In each sector $k$, 
each input is produced by a set of $n \in N$ monopolists, but the sector itself is competitive and produces using only the inputs with a production function given by

$$
y_{k}=\left(\sum_{n=1}^{N} q_{n, k}^{\left(\rho_{k}-1\right) / \rho_{k}}\right)^{\rho_{k} /\left(\rho_{k}-1\right)}
$$

We allow for the fact that $\rho_{k}$, the elasticity of substitution between varieties may be sector-specific. Cost minimization yields the price of the sector-composite as $P_{i, k}=\left(\sum_{n=1}^{N} p_{n, k}^{\left(1-\rho_{k}\right)}\right)^{1 /\left(1-\rho_{k}\right)}$ and demand for each individual input $y_{n, k}$ as

$$
q_{n, k}=y_{k}\left(\frac{P_{n, k}}{P_{k}}\right)^{-\rho_{k}}
$$

A key assumption of this preference framework is that

$$
\rho_{k}>\eta \geq 1
$$

that is, if we think of two sectors "Trousers" and "Shoes" and two shoe varieties "Reebok" and "Nike," we assume that it is easier to substitute away from Reebok to Nike than it is to substitute from shoes to trousers. We also assume that $\rho_{k}>1$ so that markups are finite.

Price Setting by Variety Monopolists. Dornbusch's main departure from Dixit and Stiglitz (1977) is that firms are non-negligible in size within a sector, so that each firm has an impact on the aggregate price index of the sector, which it takes into account when setting its price.

Each variety producer faces a constant marginal cost $\omega_{n}$, which may include iceberg transportation costs and maximizes profits subject to demand derived from (7) and (6).

Given the two-tiered utility/production setup and the fact that the production elasticity $\rho_{k}$ differs from the demand elasticity over sector composites $\eta$, the first order condition of a firm with a non-negligible market share in sector $k$ implies a pricing rule of that is dependent on the firm's market share $s_{n, k}$ :

$$
\begin{aligned}
p_{n, k}^{*} & =\frac{\varepsilon\left(s_{n, k}\right)}{\varepsilon\left(s_{n, k}\right)-\varepsilon\left(s_{n, k}\right)} \omega_{n, k} \\
\varepsilon(s) & =\left[\frac{1}{\rho_{k}}\left(1-s_{n, k}\right)+\frac{1}{\eta} s_{n, k}\right]^{-1}
\end{aligned}
$$

Since $\rho>\eta$, a firm's perceived demand elasticity is decreasing in its market share. Consequently, the equilibrium markup is increasing in the firm's market share.

This preference framework cannot easily be solved for analytically. Atkeson and Burstein (2008) show, however, that a loglinearization around the steady state results in a straightforward calibra- 
tion of how cost changes translate into prices changes. This log-linearization yields

$$
\begin{aligned}
\widehat{P}_{n, k} & =\Gamma\left(s_{n, k}\right) \widehat{s}_{n, k}+\widehat{w}_{n, k} \\
\widehat{s}_{n, k} & =\left(\rho_{k}-1\right)\left(\widehat{P}_{k}-\widehat{P}_{n, k}\right)
\end{aligned}
$$

where $\mathrm{a}^{\wedge}$ denotes a deviation in $\operatorname{logs}$ from the steady state and where $\Gamma\left(s_{n, k}\right)$ measures the responsiveness of the markup to the market share and is equal to $\Gamma\left(s_{n, k}\right)=\frac{s_{n, k}\left(1 / \eta-1 / \rho_{k}\right)}{1-\left(1-s_{n, k}\right) / \rho_{k}-s_{n, k} / \eta}>0$. We note that $\Gamma\left(s_{n, k}=0\right)=0$ and that $\Gamma\left(s_{n, k}=1\right)=\frac{1 / \eta-1 / \rho_{k}}{1-1 / \eta}>0 . \widehat{P}_{k}$ is the percentage change in the price index of sector $k$ and is equal to $\widehat{P}_{k}=\sum_{j \in N_{k}} s_{j, k} \widehat{P}_{j, k} .{ }^{14}$

\subsection{Market Structure and Pass Through}

With the log-linearized recursive pricing formula (9), it is straightforward to show how market structure affects the rate of pass-through. Since

$$
\widehat{P}_{n, k}=\Gamma\left(s_{n, k}\right)\left(\rho_{k}-1\right)\left(\widehat{P}_{k}-\widehat{P}_{n, k}\right)+\widehat{w}_{n, k},
$$

collecting $\widehat{P}_{n, k}$ terms yields a recursive pricing formula that relates each price change to a linear combination of all other price changes and the firm's cost change:

$$
\widehat{P}_{n, k}=\gamma_{n, k} \widehat{P}_{k}+\alpha_{n, k} \widehat{w}_{n, k}
$$

Here, $\gamma_{n, k}=\frac{\Gamma\left(s_{n, k}\right)\left(\rho_{k}-1\right)}{1+\Gamma\left(s_{n, k}\right)\left(\rho_{k}-1\right)}$ is the rate at which firm $n$ responds to changes in the general price level for given own costs and $\alpha_{n, k}=\frac{1}{1+\Gamma\left(s_{n, k}\right)\left(\rho_{k}-1\right)}$ is the rate at which this firm reacts to its own cost for a given general price level.

Proposition 1 The Equilibrium Price Change of firm $n$ in sector $k$ is equal to

$$
\widehat{P}_{n, k}=\underbrace{\gamma_{n, k}}_{n^{\prime} \text { s response to } P_{k}} \underbrace{\frac{\sum_{j \epsilon N_{k}} s_{j} \alpha_{j, k} \widehat{w}_{j, k}}{1-\sum_{j \epsilon N_{k}} s_{j} \gamma_{j, k}}}_{\text {Equilibrium Effect on } P_{k}}+\underbrace{\alpha_{n, k} \widehat{w}_{n, k}}_{n^{\prime} \text { s direct response to } w_{n, k}}
$$

Proof. In Appendix A.

In mathematical terms, there are two elements determining the rate of pass-through. The first element leading to pass-through is the fact that firms directly change their price in response to

\footnotetext{
${ }^{14}$ As Atkeson and Burstein (2008), our approach abstracts from nominal price stickiness. Benigno and Faia (2010), who also use a variant of the Dornbusch (1987) preference setup and assume that firms are identical examine how trade integration affects the degree of exchange rate pass through in the presence of price stickiness. In their setup, an increase of globalization is modeled as an increase in the share of foreign firms that are active in the domestic economy; they document that such globalization unambigously increases the rate of pass through also when menu costs are present.
} 
marginal cost changes. The price change resulting from this is equal to the change in the firm's marginal cost $\widehat{w}_{n, k}$ multiplied by the firm's sensitivity to its marginal costs $\alpha_{n, k}$.

The second element is the effect of the exchange rate on the general price level, which is affected by market structure via three channels. The first channel is that if the exchange rate of a trade partner moves, any firm $j$ originating from this trade partner moves prices by $\alpha_{j, k} \widehat{w}_{j, k}$. Denoting the set of firms in sector $k$ that originates from the trade partner by $N_{k, T P}$, the total impact on $\widehat{P}_{k}$ is thus equal to $\sum_{j \in N_{k, T P}} s_{j} \alpha_{j, k} \widehat{w}_{j, k}$. The first channel thus depends on the total impact of TP-firms on the general price level. The second channel through which market structure affects pass-through works through second-round amplification because all firms in the industry react to the change in the general price level, thus multiplying the initial impact by $\left(1-\sum_{j \in N_{k}} s_{j} \gamma_{j, k}\right)^{-1}$. The third channel is that the firm $n$, in turn, reacts to changes in the general price level with a rate of $\gamma_{n, k}$, which depends on its market share.

In economic terms, two elements of market structure are important for the rate of pass through: on the one hand, the market share of each individual firm affects its responsiveness to its costs and to the general price level. On the other hand, the combined market share of all firms from the trade partner determines the mass of firms that are affected by the exchange rate shock and the corresponding effect on the general price level.

In order to highlight these two effects separately, we next proceed with a simplification of the equilibrium pricing Equation (11), in which only the second channel matters: we assume that domestic firms and also firms from all trade partners are of equal size, so that only the number of firms originating from a certain country matters for pass-through.

The price response to TPC and USD movements. We next document how price react to TPC and USD shocks. For this, we assume that each firm's cost is linearly affected by the exchange rate $\Delta e_{c, t}$ and we also allow for the presence of further idiosyncratic cost shocks $\hat{\varepsilon}_{n, k}$

$$
\widehat{w}_{n, k}=\Delta e_{c, t}+\hat{\varepsilon}_{n, k} .
$$

recalling our definition of TPC and USD cost shocks $\left(\Delta e_{c, t}=\Delta U S D_{R O W-c, t}+\Delta T P C_{c, t}\right)$ implies that

$\widehat{P}_{n, k}=\left(\gamma_{n, k} \frac{\sum_{j \epsilon N_{c, k}} s_{j} \alpha_{j, k}}{1-\sum_{j \epsilon N_{k}} s_{j} \gamma_{j, k}}+\alpha_{n, k}\right) \Delta T P C_{c, t}+\left(\gamma_{n, k} \frac{\sum_{j \epsilon N_{k}} s_{j} \alpha_{j, k}}{1-\sum_{j \epsilon N_{k}} s_{j} \gamma_{j, k}}+\alpha_{n, k}\right) \Delta U S D_{R O W-c, t}+\hat{\varepsilon}_{n, k}$

where

$$
\widetilde{\varepsilon}_{n, k} \equiv \gamma_{n, k} \frac{\sum_{j \epsilon N_{k}} s_{j} \alpha_{j, k} \hat{\varepsilon}_{j, k}}{1-\sum_{j \epsilon N_{k}} s_{j} \gamma_{j, k}}+\alpha_{n, k} \hat{\varepsilon}_{n, k} .
$$

We note that the difference in the response to TPC movements and to USD movements arises because the set of firms affected by the exchange rate movement is different: For a TPC movement, 
only firms from trade partner $c$ face the exchange rate shock (thus the summation over $j \epsilon N_{c, k}$ ). For a USD movement, all importers are affected (thus the summation over $j \epsilon N_{k}$ ). To highlight this intution, we next analyze the case of equal sized firms.

Assuming Equal-Sized Firms. We first present intuition for our model by solving out the case for equal-sized firms. This allows us to explain how the model generates predictions for both price changes, pass-through and market structure. The predictions also align exactly with the cases of our reduced-form estimations.

Proposition 2 Assume that all firms are of equal size so that the total number of firms equals $N_{k}, s_{n, k}=1 / N_{k}, \gamma_{n, k}=\bar{\gamma}, \alpha_{n, k}=\bar{\alpha}$, and $\Gamma\left(s_{n, k}\right)=\bar{\Gamma} /(1-\rho)$ are equal for domestic and foreign firms. Denote the fraction of firms from the US, a TP, and the ROW by $n_{U S}, n_{T P}$, and $n_{R O W}$ with $n_{U S}+n_{T P}+n_{R O W}=1$, and corresponding price changes by $\widehat{P}_{U S}, \widehat{P}_{T P}$, and $\widehat{P}_{R O W}$. Since all prices are denominated in US Dollars and we only analyze cost shocks originating from exchange rate movements, normalize $\widehat{w}_{U S}=0$.

Then, one can show that

$$
\widehat{P}_{T P C, c}=\underbrace{\frac{1}{1-\bar{\gamma}} n_{T P} \bar{\alpha} \Delta T P C_{c, t}}_{\text {Effect of } T P C \text { on } \widehat{P}_{k}}+\underbrace{\bar{\alpha} \Delta T P C_{c, t}}_{\text {Direct Cost Effect }}+\widetilde{\varepsilon}_{n, k} .
$$

and

$$
\widehat{P}_{U S D, c}=\underbrace{\frac{1}{1-\bar{\gamma}}\left(n_{R O W}+n_{T P}\right) \bar{\alpha} \Delta U S D_{R O W-c, t}}_{\text {Effect of USD on } \widehat{P}_{k}}+\underbrace{\bar{\alpha} \Delta U S D_{R O W-c, t}}_{\text {DirectCost Effect }}+\widetilde{\varepsilon}_{n, k} .
$$

and it follows that

1. As long as the rest of the world is non-negligible, that is if $n_{R O W}>0$, pass-through following a USD movement is larger than following a TPC movement of the same size:

$$
\left(\bar{\gamma}\left(n_{R O W}+n_{T P}\right)+1-\bar{\gamma}\right)>\left(\bar{\gamma} n_{T P}+1-\bar{\gamma}\right)
$$

2. Pass-through following a TPC movement is increasing in TP market share:

$$
\frac{\partial \frac{\bar{\alpha}}{1-\gamma}\left(\bar{\gamma} n_{T P}+1-\bar{\gamma}\right)}{\partial n_{T P}}>0
$$

Proof. In Appendix A.

Allowing for Firm Heterogeneity. Not only the mass of firms, but also the entire distribution of firm size matters for pass-through. For example, for constant total exports, pass-through is larger in a sector with very small firms than in one with at least one large firm. With the precise 
definition of price changes developed in (11) above, the TPC price change now becomes

$$
\widehat{P}_{T P C, c}=\left(\gamma_{n, k} \frac{\sum_{j \epsilon N_{k, T P}} s_{j} \alpha_{j, k}}{1-\sum_{j \epsilon N_{k}} s_{j} \gamma_{j, k}}+\alpha_{n, k}\right) \Delta T P C_{c, t}+\widetilde{\varepsilon}_{n, k}
$$

where again TPC pass-through is given by the coefficients multiplying $\triangle T P C_{c, t}$. Note that comparing the price change of the individual firm (15) following a TPC movement to the price change when all firms are of equal size is different in the following way:

- The firm's individual responses to changes in the price level and marginal costs, $\gamma_{n, k}$ and $\alpha_{n, k}$, respectively, now depend on the market share of the firm.

- The first-round impulse $\sum_{j \in N_{k, T P}} s_{j} \alpha_{j, k}$ now depends on the distribution of the size of all firms originating from a TP. For example, if the TP has few large firms, $\alpha_{n, k}$ is small and so the total first round effect is small.

- The second-round effect depends on the distribution of the size of all firms in the industry. This is irrespective of the origin, that is, the entire market structure of the sector matters for pass-through.

\section{Empirical Analysis: Comparing Actual and Predicted Price Changes}

This section shows that we can match empirically observed price changes and estimated passthrough given our exchange rate decomposition, information on the market structure of the entire sector, and the above-discussed preferences. We also show that the results are economically important in that they can explain a substantial part of the differences in pass-through rates across countries.

Our exercise maps the above-described theoretical pricing framework (15) to our approach of identifying TPC movements, making use of aggregate information on import quantities and other sector-specific information. We focus mostly on pass-through following TPC shocks. The reason for this is that we have more variation for the case of TPC movements than for USD movements: while the USD pass-through rate varies only across sectors, the TPC rates also varies across trade partners. We believe that this additional variation is important, as we examine only a limited aspect of how "market structure" affects pass-through: in this paper, market structure refers to the number and size distribution of the firms that are affected by a specific TPC movement. Obviously also other aspects of market structure influence pass-through, for example the characteristics of the traded product or the underlying production technology. Our analysis focuses on TPC passthrough rates, where we can explain differences in pass-through rates within rather than across sectors. ${ }^{15}$

\footnotetext{
${ }^{15}$ In particular, we are also concerned that many sector characteristics that affect a sector's general openness also
} 
We first test the predictions of the model using our micro data. For this set of tests, we construct theoretically predicted price changes following TPC shocks. We then relate the predicted to the actually observed price changes. Second, we aggregate information up to show that the developed theory is economically significant in explaining aggregate rates of pass-through. For example, we document that our models can explain around a third of the variation in TPC pass-through rates across countries.

Overall, we find that there is very strong evidence that we can match price changes, and we also show that the results are economically important in that they can explain a substantial part of the differences in pass-through rates across countries.

\subsection{Mapping the model to the BLS data}

Here, we describe how we take the model to the data, matching actual price changes to the ones predicted by the model calibrated with TPC movements, a firm's market share, the mass of competitors originating from the same country, and the entire market structure in its industry. We include monthly information on market shares at the firm level using information delivered by both external data and the structure of our model.

Firm's Market Shares. In taking the model to the data, we need to overcome one major limitation of the BLS data, which is that it does not include data on the sales of individual firms. We thus first add country-specific trade flows that are sufficiently dissagregated so that we know the actual market share of most (but not all) firms. We then take two alternative approaches to either infer or simulate the size distribution of all fims. Our main approach is to use information on prices contained in the BLS dataset to infer firm's market shares. Our alternative approach is to assume an exogenously given distribution from which firm productivities are drawn.

We start by adding an extremely disaggregated trade dataset on country-specific import volume to our BLS simulations. We use country-specific US import data at the HS 10-digit level of disaggregation from Feenstra et al. (2002), who update the data of Feenstra (1996). The main advantage of using this dissagregate data is that the number of firms from a specific trade partner and in a specific HS-10 digit code is very small: there are 18320 different HS 10-digit codes, which is comparable in magnitude to the overall BLS sample size and in fact much larger than the typical number of firms originating from a given trade partner in a given month.

Indeed, for $61.2 \%$ of the observations in our sample, there is only one active firm per trade partner-HS10-year-month combination and thus we precisely know the firm's market share within its industry. We can use this subsample to gauge whether the quality heterogeneity issue is of importance by running a robustness test in which we only consider sectors where there is one firm per trade partner.

directly influence the rate of pass-through (see Campa and Goldberg (2005); Goldberg and Campa (2010), Goldberg and Tille (2009), and Gopinath and Itskhoki (2011)). 
Also in the remainder of the sample, there are typically very few firms per TP-HS10d-yearmonth combination. In $18 \%$ of the observations, there are 2 firms per combination. In $8.7 \%$ respectively $4.8 \%$ of the combinations there are 3 and 4 firms. There are 6 or more firms per combination in fewer than $2 \%$ of the observations. The average number of firms per combination is 1.92 and the maximum is 54 . For the cases in which there is more than one firm, we adopt two different strategies to construct market shares.

Our main strategy is to construct market shares by using the information contained in individual prices to infer market shares: it follows from the model that market shares are proportional to $p^{\left(1-\rho_{k}\right)} / \sum p^{\left(1-\rho_{k}\right)}$. We use this relationship to infer the distribution of firm size from prices in conjunction with available disaggregated data on bilateral imports and domestic production by sector. Thus, within each 10-digit HS industry, the market share of a given firm $n \in N_{T P, k}$ from country $T P$ is equal to

$$
s_{n, k}=\left(1-m_{U S, k}\right) m_{T P, k} \frac{p_{n, k}^{\left(1-\rho_{k}\right)}}{\sum_{j \in N_{k, T P}} p_{j, k}^{\left(1-\rho_{k}\right)}},
$$

where $m_{U S, k}$ is the market share of all US domestic firms and $m_{T P, k}$ is the sectoral import share of country $T P$.

Our inference of market shares is robust to the presence of HS-10-digit-specific cross-country variation in good quality as documented for example by Khandelwal (2010), since we use the actual information on the trade partner's overall market share $\left(1-m_{U S, k}\right) m_{T P, k}$. If the average quality of imports from a specific trade partner is high, this is reflected in $m_{T P, k}$. If US goods are of higher or worse quality than imports, this is reflected in $m_{U S, k}$. Thus, adding measures of average country-specific quality such as the one developed in Hallak and Schott (2011) would not improve our results.

We note that our strategy for infering market shares is however invalid if there is systematic variation of good quality across the different firms originating from the same trade partner and in the same HS-10-digit industry. While we believe the latter quality heterogeneity within such finely defined good categories and also within the same trade partner likely to be very small, we also present an alternative estimate of market shares robust to this critique in which we follow Atkeson and Burstein (2008) and simulate firm productivities within HS-10-digit-trade-partner combinations rather than infering them from the data. We describe the latter in the robustness analysis. $^{16}$

A second important detail of mapping the developed pricing theory to the BLS data concerns

\footnotetext{
${ }^{16}$ It is also noteworthy that quality heterogeneity within HS-10digit goods originating from the same trade partner is likely to be very small. To the best of our knowledge, there is no empirical evidence that quality heterogeneity at such a fine level of disaggregation exists for firms from the same trade partner. For example, Khandelwal (2010) establishes quality heterogeneity at this level of aggregation across trade partners but not within. Alessandria and Kaboski (2011) identify pairs of HS-10 products that represent lower- and higher-quality variants of the same good such as fresh vs. frozen or new vs. used. Their quality comparisons is across HS-10 digit rather than within.
} 
the prices of domestic firms. In addition to its dependence on the market structure of all importers, the theoretical price response given by our model also depends on the market structure of domestic competitors. While information on domestic firms is not included in the BLS import price data, we do, however, have these prices available in a different dataset, the BLS domestic producer price data. We follow two approaches. In the first, we assume that importers only compete with each other. In the second, we calculate the price response of domestic firms and feed it back to the pass through response.

Competition with Domestic Firms For each sector, we use the aggregate weighted price changes of domestic firms in our estimation computed from the BLS domestic producer price data at the six-digit NAICS level. Denoting the change in domestic prices by $\widehat{P}_{k, U S} \equiv \sum_{j \in N_{k, U S}} s_{j} \widehat{P}_{k}$, the recursive pricing formula (21) can be shown to equal

$$
\widehat{P}_{k}=m_{U S, k} \widehat{P}_{k, U S}+\sum_{j \in N_{k, f o r}} s_{j} \gamma_{j, k} \widehat{P}_{k, j}+\sum_{j \in N_{k, f o r}} s_{j} \alpha_{j, k} \widehat{w}_{j, k}
$$

Further algebra directly leads to the following expression for TPC-induced price changes:

Corollary 3 Assume that foreign firms and domestic firms do not compete directly within each industry. The pricing response is:

$$
\widehat{P}_{T P C}=\left(\frac{\gamma_{n, k} \sum_{j \epsilon N_{k, T P}} \widetilde{s_{j}} \alpha_{j, k}}{1-\sum_{j \epsilon N_{k, f o r}} \widetilde{s_{j}} \gamma_{j, k}}+\alpha_{n, k}\right) \Delta T P C_{c, t}
$$

where the market shares $\widetilde{s_{j}}$ are constructed assuming that $m_{U S, k}=0$, that is, that only the market structure of importers matters and $N_{k, \text { for }}$ denotes the number of foreign firms in sector $k$.

Corollary 4 Assume that foreign firms and domestic firms do compete directly within each industry. The pricing response is:

$$
\widehat{P}_{T P C}=\left(\gamma_{n, k} \frac{m_{U S, k} \rho_{u s, T P}+\sum_{j \in N_{k, T P}} s_{j} \alpha_{j, k}}{1-\sum_{j \in N_{k, f o r}} s_{j} \gamma_{j, k}}+\alpha_{n, k}\right) \Delta T P C_{c, t},
$$

where $\rho_{u s, T P} \equiv \frac{\partial P_{k, U S}}{\partial w_{T P}}$ is the rate at which US domestic prices respond to the exchange rate of TP and $\rho_{u s, T P}$ is empirically estimated. Again, TPC pass-through is given by the coefficient multiplying $\hat{\omega}_{T P}$.

With these important details of our procedure in mind, our calibration exercise is the following:

- We adopt one of the following definitions of a "sector:"

1. We define a sector to be a six-digit NAICS industry. We directly have the TP-six-digit 
NAICS market shares available and only need to allocate the TP-sector market shares to the various firms from that TP according to (16).

2. We define a sector to be a ten-digit HS sector and assume that the TP's overall market share at the HS ten-digit level is the same as the one in the six-digit NAICS sector.

- We then allocate the total market share to the various firms from each TP according to either

1. Inferring firm market shares prices following Equation (16).

2. Simulating market shares following Equation (20).

- We calculate the theoretically predicted price changes and pass-through rate for each firm in the BLS sample using the constructed market shares, US domestic price changes, and the sectoral elasticity of substitution. We use either:

1. The pricing formula (18) that does take into account domestic prices.

2. The pricing formula (17) that does not take into account the price change of domestic firms

- We use a value of the $\rho=10$ for the elasticity of substitution within sectors and $\eta=1.01$ for the elasticity of substitutions across sectors. We also run a specification that uses the sectorspecific estimate of $\rho$ from Broda and Weinstein (2006). The value of 1.01 for $\eta$ is taken from Atkeson and Burstein (2008). It implies that a monopolist will have a high markup, but we note that the results presented below are robust to using a higher value of $\eta$.

1. As a baseline estimate for $\rho$, the elasticity of substitution between varieties within a sector, we take 10, the baseline estimate of Atkeson and Burstein (2008).

2. As a robustness check, we also use the sector-specific elasticity estimates from Broda and Weinstein (2006) directly. While Broda and Weinstein (2006) estimates are sectorspecific thus adding more information, they are constructed assuming a model structure that may conflict with the one used in this paper (see Feenstra (1994) for the details of this estimation). Therefore, our baseline assumption is to use a common $\rho$ across sectors.

- We then compare the actual price change of each good in our sample to the price change we predict, that is, the product of the TPC or USD exchange rate movement and the predicted firm-specific pass-through rate (either (18) or (17)). 


\subsection{Baseline Results: The Response of Individual Prices}

In this subsection, we document our main empirical results and show that the above-developed theory can significantly explain import price adjustments when it is calibrated using our exchange rate decomposition and information on the distribution of the origin of firms and their market shares. We start by documenting how well we can match the distribution of actual price changes with our most basic prediction of price changes following TPC movements and we document how alternative parameter choices affect this result. Second, we examine how well price changes following USD movements (or USD and TPC movements jointly) can be explained by our predictions.

Baseline Results. We begin by documenting the results for our baseline predictions of price changes. How well can actual price changes be explained by predicted ones? We estimate a stacked regression to answer this question, regressing monthly import price changes on up to 24 monthly lags of the respective predicted TPC-movements-induced price changes; in each month, we multiply the TPC exchange rate change with the theoretically predicted rate of pass-through constructed in Equation (17) using only the TPC movement to construct these theoretically predicted price change $\Delta p_{i, c, t}^{\text {pred,TPC}}$, which are our lagged regressors. We thus estimate:

$$
\Delta p_{i, c, t}^{a c t}=\alpha_{c}+\sum_{j=1}^{25} \beta_{j} \Delta p_{i, c, t-j+1}^{p r e d, T P C}+\epsilon_{i, c, t} .
$$

Note that Equation (19) is similar to the baseline pass-through estimation (3) with the exchange rate replaced by the predicted price change. In Table 1 we report the sum of the $\beta_{j}$ coefficients, that is, the cumulative two-year response of actual prices to our predictions.

We find that predicted price changes are significant determinants of actual price changes. Columns (1) to (3) of Table 1 present unconditional price change estimations that include the entire sample. The predicted price changes are constructed assuming that competition takes place within NAICS six-digit industries. In column (1), the predicted price change is constructed assuming that the elasticity of substitution $\rho$ between varieties is equal to 10 . In column (2), we allow for the elasticity of substitution between varieties to be sector-specific using the values from Broda and Weinstein (2006). In column (3), we again assume that the elasticity is equal to 10 in all sectors, but we restrict the sample to those sectors conservatively classified by Rauch (1999) as heterogeneous. The reason for the latter restriction is that it is likely that our pricing theory can predict prices better in differentiated goods sectors rather than in sectors with homogenous goods.

However, we also find that the coefficients of actual price changes are surprisingly small; they range from 0.09 to 0.1 . Also the overall fit of the model is only moderate: the $R^{2}$ varies from $0.6 \%$ to $1.1 \%$.

An immediate guess is that this low magnitude is the consequence of nominal price rigidities. Since our pricing theory does not take into account such rigidities, from column (4) onwards, we 
follow Gopinath and Rigobon (2008) and restrict the sample to instances in which we observe actual price changes. Mirroring the previous three specifications, the predictions in columns (4) and (6) assume that the elasticity of substitution is equal to 10, while the sector-specific value for this variable from Broda and Weinstein (2006) is used in (5). Column (6) restricts the sample to those sectors classified by Rauch (1999) to be heterogeneous.

The restriction to instances in which prices change has a marked impact on the estimated coefficients, which are equal to 0.42 when assuming $\rho=10$ and even equal to 0.76 in the differentiated goods subsample. The coefficient of 0.76 in column (6) is actually not significantly different from 1 , that is, we even cannot reject the hypothesis that in this subsample, the above developed theory can explain pricing-to-market decisions 1-to-1. The overall fit of the model improves by an order of magnitude: the $R^{2}$ is $3.8 \%$ in the full sample and $11.2 \%$ in the differentiated goods subsample. ${ }^{17}$

An important choice concerns the definition of the "market" firms compete in. Our assumption in columns (1) to (6) is that firms compete within NAICS six-digit industries, which might be too wide for some sectors. For example, this assumption seems realistic in the car industry (336111 - Automobile Manufacturing, which does not include heavy trucks) as nearly all type of cars for personal transport are more or less in direct competition. However, in other sectors such as Laboratory Apparatus and Furniture (339111), very distinct goods that hardly ever directly compete are classified in the same NAICS six-digit industry. Therefore, we next compare actual and predicted price changes assuming that competition happens within an HS ten-digit sector, the finest level of aggregation available in the BLS dataset.

When comparing actual and predicted price changes at this highly disaggregated level, we again find a statistically highly significant fit. This holds both when assuming that $\rho=10$ or that $\rho$ is as in Broda and Weinstein (2006). Columns (7) and (8) show this result. The same holds when restricting the sample to those sectors classified by Rauch (1999) to be heterogeneous as shown in column (9), again assuming $\rho=10$. In terms of quantitative fit, we find that the predictions assuming that firms compete at the very fine HS ten-digit level actually performs similarly as when assuming that firms compete within NAICS six-digit industries. However, we note that HS ten-digit is a very fine disaggregation that is realistically too narrow of a definition of a market, and we thus keep the definition of NAICS six-digit industries in the remainder of the analysis.

Overall Fit of the Baseline Prediction. Table 1 documents that the predicted price changes correlate significantly with actual price changes and that the $R^{2}$ of the model is quite high; we next demonstrate graphically how well we can match the overall distribution of price changes and how

\footnotetext{
${ }^{17}$ We note that our conditional pass-through specification slightly differs from the conditional specification estimated in Gopinath and Rigobon (2008). Gopinath and Rigobon estimate the conditional pass-through rate between two actual price change dates rather than for a fixed $24-$ months horizon as in Table 1 . The reason for this difference is that what matters for our preferences is not only whether the firm itself changes its price, but also, whether its competitors have changed their price, which is more likely over longer horizon (our pass-through equation (12) assumes that all prices are flexible so a true conditional pass through estimation would restrict the sample to dates on which all prices in a sector change; this happens only in a few instances).
} 
much our theory improves our understanding of pricing-to-market decisions.

Figure 4 presents three kernel density estimates, corresponding to the distribution of actual price changes (blue line), of price changes predicted from the Dornbusch-Atkeson-Burstein framework (red line), and an alternative "benchmark" model that assumes that firms charge constant markups (green line). All three lines present the distribution of log price changes in the sample restricted to nonzero actual price changes. That is, they compare the conditional performance of the model. For the price changes predicted from the Dornbusch-Atkeson-Burstein framework we assume that competition takes place within NAICS six-digit industries and that $\rho=10$. The benchmark model serves to compare the importance of allowing for variable markups in the Dornbusch-AtkesonBurstein framework analyzed above compared to a standard preference framework with isoelastic demand. All three lines display the 1-month actual and predicted log price changes.

Even the distribution of nonzero actual price changes has a pronounced mode around 0, demonstrating the importance of small price changes in the data. Interestingly, while the constant markup benchmark model cannot match this spike, the Dornbusch-Atkeson-Burstein predictions can do so quite well and it even overpredicts the frequency of small price changes. We note that the construction of the Dornbusch-Atkeson-Burstein price prediction and the constant markups prediction use the same underlying TPC exchange rate changes, so that the only difference between these two predictions are the variable markups in the former prediction. Figure 4 thus highlights graphically that such variable markups are important for matching the distribution of actual price changes. A limitation of our model is that we cannot very well explain large actual price changes, which is due to one-month horizon of the graph.

Price Changes Following USD and TPC Movements. The previous table has examined exclusively whether TPC-induced predicted price changes can explain actual price changes. Table 2 next examines whether we can explain price changes following USD movements and also, whether we can explain actual price changes following USD and TPC movements jointly.

In Table 2 we repeat the estimation of Table 1 and investigate whether predicted price movements following USD movements can explain actual price changes. We again estimate a stacked regression and regress monthly import price changes on 24 monthly lags of the respective predicted USD-movements-induced price change; that is, in each month, we multiply the USD exchange rate change with the theoretically predicted rate of pass-through constructed in Equation (17). We set the TPC movement to 0 in Columns (1) to (6). All predictions are constructed assuming that competition takes place within NAICS six-digit industries.

In the unconditional price change regressions of columns (1) to (3), we find that predicted price changes following USD-movements are also significant determinants of exchange rates. In column (1), the predictions are constructed assuming that $\rho=10$, while $\rho$ is as in Broda and Weinstein (2006) in the next column. In column (3), $\rho$ is equal to 10 and the sample is restricted to heterogeneous goods sectors as classified by Rauch (1999). The uncovered coefficients are highly 
significant and the coefficients are larger in magnitude than the coefficients than the corresponding coefficients in 1 examining the actual price response following TPC movements.

The coefficients of the predicted price changes following USD movements are indiscernible from 1 in the conditional estimations estimated in columns (4) to (6). These three specifications are for the three cases: $\rho=10, \rho$ from Broda Weinstein, and heterogeneous sectors with $\rho=10$. We note that although the coefficients for the USD-movement induced price predictions are larger than for the TPC-movement induced price predictions, the $R^{2} \mathrm{~s}$ in Table 2 are somewhat smaller than the ones in Table 1 as TPCs are more variable than the USD.

The coefficients of the predicted price changes following USD movements are indiscernible from 1 also in the next three conditional estimations in columns (7) to (9), which include both the price changes predicted from TPC movements and the price changes predicted from USD movements. The coefficient of the predicted price changes following TPC movements are smaller than 1 and are comparable to the ones in Table 1 (see columns (4) to (6) in Table 1) except in the differentiated goods subsample in column (6), where we find that also the TPC-induced price change affects actual price changes at a rate not different from 1.

The two tables presented in this section have documented the main empirical finding of this paper. Table 1 documents that our baseline findings are statistically significant and economically important. Table 2 examines the role of predicted price changes following USD and TPC movements. Both are significant determinants of actual price changes; together, they can explain up to $20 \%$ of the entire variation in conditional price changes.

\subsection{Robustness Analysis}

We next examine the robustness of our results. For simplicity, the robustness exercises below present estimations constructed assuming $\rho=10$.

Quality Heterogeneity and the Construction of Firm's Market Shares. As a first robustness exercise, we address the important concern that within HS ten-digit industries there could be variations in good quality across the different firms originating from the same trade partners. Quality heterogeneity of this form would invalidate our allocation of market shares as prices and good quality are likely to be positively correlated as shown in Baldwin and Harrigan (2011) and Johnson (2012).

Our first approach to address this issue is to work with the subset of HS ten-digit sector-TP combinations with only one active firm. In these instances, the firm's market share $s_{n, k}$ is equal to $\left(1-m_{U S, k}\right) m_{T P, k}$, that is, we do not use the information on prices as we allocate the TP's market share to the single firm. As we discuss also above, given that there are around 18000 HS ten-digit sectors, actually $61 \%$ of the sample falls into this subset. 
We find that restricting the sample in this way deteriorates the fit of the pricing model in the set of unconditional estimations, yet improves it in the conditional estimations. Columns (1) and (2) of Table 3 present unconditional regressions estimating the response of actual to predicted price changes in this subsample. Both simulations assume that competition happens within NAICS sixdigit firms. Column (1) includes all HS ten-digit sector-TP combinations with only one active firm and column (2) further restricts the sample to heterogeneous goods sectors as classified by Rauch (1999). Columns (3) and (4) repeat the same specifications as do (1) and (2) respectively, but present conditional regressions. For the unconditional regressions, the coefficients of the predicted price changes and the $R^{2}$ are comparable or somewhat smaller compared to the estimation in the full sample (see Table 1). For the conditional regressions, the coefficients of the predicted price changes and the $R^{2}$ are actually substantially larger compared to the estimation in the full sample (see Table 1). In the differentiated goods subsample, the fit of the model actually improves to $31 \%$.

The finding that the conditional fit of the model is much improved by the restriction to sector-TP combinations with only one active firm is not puzzling: after all, such a restriction over-represents firms with large market shares for which our theory might be a better description than for small firms.

Our second approach to deal with the issue of quality heterogeneity is to follow Atkeson and Burstein (2008) and simulate firm productivity rather than inferring it from prices. For this, we first generate productivity draws and assume that each firm $n$ draws its idiosyncratic productivity $z_{n}$ from a $\log$-normal distribution $\left(\log z_{n} \sim \mathrm{N}\left(0, \sigma^{2}\right)\right.$, where $\sigma^{2}=0.385$ as in Atkeson and Burstein (2008). For the given realizations of $z_{n}$ within each sector, we then compute numerically

$$
s_{n, k}=\left(1-m_{U S, k}\right) m_{T P, k} \frac{p_{n, k}^{*}\left(1-\rho_{k}\right)}{\sum_{j \in N_{k, T P}} p_{j, k}^{*}\left(1-\rho_{k}\right)},
$$

where $p_{n, k}^{*}$ is the firm's optimal prize given by (8) setting $\omega_{n, k}=k_{c, k} / z_{n} . k_{c, k}$ is a TP-HS10 specific cost shifter that cancels out of $(8) .{ }^{18}$

We note that because our analysis is at a finer level of disaggregation and because we augment the BLS data by trade-partner specific quantity data, the importance of the random productivity draws for our simulations is much smaller than in Atkeson and Burstein (2008). In the latter work, the main analysis is at the six-digit NAICS level of disaggregation and in their main sample, there are on average around 700 firms in each industry for which a random productivity shock is used to simulate market shares. In our sample, there are on average 1.92 firms per TP-HS combination for which we draw a random productivity shock and most of the variation in firm-specific market

\footnotetext{
${ }^{18}$ We note that the system of equations (20) and (8) for all firms within a sector is non-linear. Owing to software restrictions at the BLS, we cannot solve this system exactly, but we can solve it by iteration starting with firms chargin a constant markup and then iterating (20) and (8). The latter iteration converges to a unique equilibrium as low cost firms charge higher markups.
} 
shares derives from the variation in $m_{T P, k}$.

Again, we find a highly significant relation between the predicted and actual price changes also for the case of simulated market shares for both conditional and unconditional estimations. Columns (5) and (6) of Table 3 presents unconditional regressions estimating the response of actual to predicted price changes using the simulated market shares. Both simulations assume that competition happens within NAICS six-digit firms. Column (5) includes the full sample while column (6) restricts the sample to heterogeneous goods sectors as classified by Rauch (1999). Columns (7) and (8) repeat the same specifications as do (5) and (6) respectively, but present conditional regressions.

The results when using the simulated market shares are roughly comparable to our baseline approach. The $R^{2} s$ of the models in columns (5) and (7) are somewhat larger than the corresponding ones in the baseline estimation; in contrast, in the differentiated goods subsample in columns (6) and (8), the $R^{2} s$ in the baseline results are somewhat higher than in the one of Table 3 . While these results leave us without any firm conclusion regarding as to what is the "better" way of constructing market shares, we conclude that inferring market shares from the observed distribution of prices at a highly aggregated level and adjusted for cross-country difference in quality definitely does not lead to biases that explain the results presented in this paper.

What is Driving Our Results? We next show how the addition of different fixed effects alters our results. For this, Table 4 again estimates stacked regression models (19) with the monthly actual price change as dependent variable and 24 lags of the predicted price change as independent variables.

We find that our results are not driven by aggregate patterns or mere cross-country differences, but by more subtle differences in market structure within trade partners. Columns (1) to (5) present unconditional price change estimations that include the entire sample. Columns (6) to (10) present conditional price change estimations, that is, the sample is restricted to those observations in which the actual prices change is nonzero. The predicted price changes are constructed assuming that competition takes place within NAICS six-digit industries and that $\rho=10$.

Column (1) documents that these above presente results are not driven by cross-country differences. In the absorption regression of column (1), we add trade-partner dummies to the estimation to soak up all cross-country variation, resulting in a slightly higher coefficient of 0.1 for the case of the unconditional response rate (see column (1) of Table 4 and compare to column (1) of Table 1). Column (6) documents that the addition of trade partner effects substantially increases the coefficient from 0.42 to 0.61 in the conditional regression (compare to column (4) of Table 1).

Also the addition of sector fixed effects to account for technological charateristics that might affect price responses does not affect our results. Columns (2) and (7) add sector-fixed effects (sixdigit) to the unconditional (column (2)) and conditional (column (7)) estimation, with resulting point estimates that are comparable to the baseline estimate. We note that the point estimates are 
unaffected despite the sector-fixed effects explaining a substantial share of the variation (see the high $R^{2}$ in (2) and (7)).

Columns (3) to (5) next demonstrate that seasonality in pricing is not behind our results. Column (3) adds month fixed effects, column (4) months fixed effects for every trade partner, and column (5) months fixed effects for every sector. In all three specifications, the point estimates are not affected much by this inclusion. The same is true in the conditional estimations in columns (8) to (10) (except that the inclusion of trade partner-months fixed effects in (9) again results in a coefficient of 0.61 as in column (6)).

Competition with Domestic Firms. We next investigate whether importers compete with domestic firms. As we explain above, a main limitation of our data is that we do not have information on the size distribution of domestic firms. However, we do have information on the price changes of domestic firms in a different data set, which we can incorporate into pricing formula (see Equation (18)).

Table 5 presents the results when using the price predictions that also incorporate the pricing response of domestic firms. We note that we do interpret the results of these estimations with care as the prices of domestic and foreign firms might commove for many other reasons than the exchange rate. Instead, we believe that the estimated coefficients are of interest when contrasted with the ones in Table 1. That is, it makes sense to analyze the effect of adding the information contained in domestic prices to the price simulations that assume that importers compete only with other importers.

The addition of information on domestic prices leaves the result surprisingly unchanged. Columns (1) and (2) of Table 5 present unconditional regressions estimating the response of actual to predicted price changes, where the predictions are constructed assuming that domestic firms compete with domestic prices. Both simulations assume that $\rho=10$, that competition happens within NAICS six-digit firms, and that importers do compete with domestic firms and the price response is given by (18). Column (4) includes the full sample, while column (4) restricts the sample to heterogeneous goods sectors as classified by Rauch (1999). Columns (3) and (4) repeat the same specifications as do (1) and (2) respectively, but present conditional regressions. The unconditional point estimates are slightly higher than the respective estimates in Table 5 and the conditional ones are quite a bit higher. This result is surprising as firms' market shares are substantially lower when we assume that firms also compete with domestic firms $\left(m_{U S, k}\right.$ is typically $\left.60 \%\right)$, and so the predicted price changes are affected substantially by assuming that importers do compete with domestic firms. ${ }^{19}$

Excluding China and Commodity Exporters. Among the large US trade partners, several stand out because they export mostly commodities or commodity-intensive goods. Given that the

\footnotetext{
${ }^{19}$ We believe that further research in the area of the competition structure between foreign and domestic firms is necessary, but this falls outside the scope of this paper.
} 
currencies of these countries might mostly be driven by commodity price fluctuations that also affect the prices of these goods, we next exclude Canada, Norway and New Zealand from our analysis. We also exclude China as it managed its exchange rate during most of the sample period.

We find that the exclusion of this group of countries substantially improves the fit or our model. Columns (5) and (6) of Table 5 present unconditional regressions estimating the response of actual to predicted price changes in this subsample. Both simulations assume that $\rho=10$, that competition happens within NAICS six-digit firms, and that importers do not compete with domestic firms. Column (5) excludes Canada, China, Norway and New Zealand, while column (6) further restricts the sample to heterogeneous goods sectors as classified by Rauch (1999). Columns (7) and (8) repeat the same specifications as do (5) and (6) respectively, but present conditional regressions. Excluding China and the commodity exporters leads to both substantiall improvements in the $R^{2}$ of the estimations and to significantly larger coefficients.

Overall, we conclude that our findings are robust in the sense that they are not dependent on knife-edge parameter choices or other choices when constructing the predictions and that furthermore, variations of parameters or other choices seem to influence the results in economically reasonable directions.

\section{The Aggregate Importance of Market Structure}

Above, we have demonstrated that the developed theoretical predictions can explain price changes quite well. We next demonstrate that it can explain pass through rates similarly well. Our sample in this section is much smaller than for price changes since the estimation of one pass-through rate requires many observations. However, the economic significance of our results comes out much more clearly as we can show how much of pass-through is explained by market structure.

Overall, we want to document the extent to which market structure explains differences in passthrough rates, where "market structure" here only refers to the number and size distribution of the firms that are affected by a specific TPC movement and the size distribution of all other firms in the sector. Obviously, other aspects of market structure influence pass-through rates, for example the characteristics of the traded product or the underlying production technology. Our analysis in this subsection accounts for the fact that we only examine one aspect of market structure by focusing on whether we can explain differences in pass-through rates within rather than across sectors. For example, we examine how the number and size distribution of German machinery producers is different from the number and size distribution of South Korean machinery producers, how these differences translate into different predicted TPC pass-through rates, and finally, we examine how the differences in the predicted TPC pass-through rates correlate with differences in actual TPC pass-through rates.

As a first step, we estimate the trade partner-specific TPC pass-through rate at the sectoral 
level, that is, we estimate the TPC pass-through rate for each sector and TP combination. Because such estimation requires a minimum number of observations, we estimate pass-through rates at the two-digit NAICS level rather than at finer levels of disaggregation, resulting in 62 such two-digit NAICS-TPC pass-through rates. For each of these sector-TP combinations, we also construct the theoretical prediction of TPC pass-through. For these predictions, we use Equation (17) assuming that importers only compete with other importers and that competition happens at the NAICS six-digit level.

As a second step, to account for the fact that pass-through rates might differ across sectors for reasons other than the trade partner's firm size distribution, we next demean each of the sectorTP-specific pass-through by the sector-specific averages. For better comparability, we also demean predicted TPC pass-through. ${ }^{20}$

Figure 5 shows that predicted pass-through rates can explain a sizeable part of the variation in actual pass-through rates across sectors and trade partners. The figure presents a scatter plot relating estimated to predicted pass-through rates. The vertical axis displays the estimated sectorTP-specific pass-through rate and the horizontal axis displays the according predicted rate. The fitted line from a volume-weighted regression has a slope of 0.63 that is significant at the $1 \%$ level, while the $R^{2}$ associated with this regression is equal to $17.6 \%$.

Figure 6 next provides strong evidence that the predicted pass-through rates can explain a sizeable part of the variation in actual pass-through rates at the country-level. For this figure, we aggregate the pass-through rates at the country level using medians. ${ }^{21}$ The vertical axis of Figure 6 presents the deviation of a country's actual average TPC pass-through rate from the TPC pass-through rate that is expected based on the country's sectoral composition of its exports. The horizontal axis measures, by the same token, whether we expect the TPC pass-through rate to be higher or lower than average based on the size distribution of firms within all the sectors. For example, Denmark's TPC pass-through rate is estimated 18\% higher than what is expected based on Denmark's export composition. The fitted line from a volume-weighted regression in Figure 6 suggests that around $16 \%$ of this is due to the size distribution of Danish firms.

While there are also outliers, the overall fit of the theory to the data is quite convincing. The slope of the fitted line is 0.82 (significant at the $1 \%$ level even with only 16 observations) and the

\footnotetext{
${ }^{20}$ Note that when we demean the predicted TPC pass-through rate, we demean by the overall average pass-through rate and not the sector-specific one. We do this as in the construction of the predicted TPC pass-through, we use information on the market share distribution only but no other sector-specific information. Demeaning the TPC passthrough predictions at the sectoral level would thus eliminate information on the average market share distribution across trade partners. Nevertheless, it is noteworthy that for the conclusions drawn from the figures below, it is not of importance whether the predicted TPC pass-through rate are demeaned by the overall mean or the sector-specific mean.

${ }^{21}$ For this aggregation, it is important to note that since each estimated sectoral pass-through rate is demeaned at the sectoral level, the resulting aggregate country-specific average TPC pass-through rate is unaffected by the composition of the country's export basket. The latter fact is important as there are quite sizeable differences in the sectoral composition of exports across trade partners, which also explain some of the variation in pass-through rates across countries (see for example Campa and Goldberg (2005); Goldberg and Campa (2010)).
} 
$R^{2}$ is around $36 \%$. We conclude that the theory presented in this paper, in combination with the relevant underlying micro-information from the BLS, can substantially improve our understanding of pricing decisions and exchange rate pass-through in import markets.

\section{Conclusion}

There is now an ample notion in the literature that price complementarities and the way in which they affect the pricing decisions of importers are behind the low average long-run pass-through rates the empirical literature consistently finds.

We contribute to this literature by identifying how exchange rate shocks affect the market environment differently in different sectors depending on the mass and size distribution of firms that is affected by a particular exchange rate shock.

We calibrate the preferences of Dornbusch (1987) and Atkeson and Burstein (2008) to examine to which extent a parsimonious model of price complementarities can match empirically observed price changes and pass-through rates when using decomposed exchange rate shocks and micro information on a sector's entire market structure.

Overall, we conclude that this theory is quite powerful in explaining how firms adjust prices in response to exchange rate movements. In our micro data, our predictions are highly significant determinants of actual price changes and, depending on the specification, the estimated coefficients are close to one. Second, at the aggregate level, our calibrations can explain much of the heterogeneity in pass-through rates across countries that the exchange rate pass-through literature typically uncovers.

\section{References}

Andrade, P., M. Carre, And A. Benassy-Quere (2012): "TVA et taux de marge: Une analyse empirique sur données d'entreprises," Working paper, Banque de France, LEDa-SDFi and Ecole d'Economie de Paris.

Atkeson, A. And A. Burstein (2008): "Pricing-to-Market, Trade Costs, and International Relative Prices," American Economic Review, 98, 1998-2031.

Auer, R. (2012): "'Exchange Rate Pass Through, Domestic Competition, and Inflation - Evidence from the 2005/08 Revaluation of the Renminbi," Cesifo working paper series 3759, CESifo Group Munich.

Auer, R., T. Chaney, And P. Saure (2012): "Quality Pricing-to-Market," GMPI Working Paper 125, Federal Reserve Bank of Dallas.

Bacchetta, P. And E. van Wincoop (2003): "Why Do Consumer Prices React Less Than Import Prices to Exchange Rates?" Journal of the European Economic Association, 1, 662-670. 
(2005): "A Theory of the Currency Denomination of International Trade," Journal of International Economics, 67, 295-319.

Baldwin, R. And J. Harrigan (2011): "Zeros, Quality, and Space: Trade Theory and Trade Evidence," American Economic Journal: Microeconomics, 3, 60-88.

Baxter, M. And A. LAndry (2010): "IKEA: Products, Pricing and Pass-Through," Working paper, Boston University and Federal Reserve Bank of Dallas.

Benigno, P. And E. Faia (2010): "Globalization, Pass-Through and Inflation Dynamic," NBER Working Papers 15842, National Bureau of Economic Research.

Bergin, P. R. And R. C. Feenstra (2009): "Pass-Through of Exchange Rates and Competition between Floaters and Fixers," Journal of Money, Credit and Banking, 41, 35-70.

Berman, N., P. Martin, and T. Mayer (2012): "How Do Different Exporters React To Exchange Rate Changes?" Forthcoming, Quarterly Journal of Economics.

Bils, M. AND P. J. KLenow (2004): "Some Evidence on the Importance of Sticky Prices," Journal of Political Economy, 112, 947-985.

Broda, C. And D. E. Weinstein (2006): "Globalization and the Gains from Variety," Quarterly Journal of Economics, 121, 541-585.

Burstein, A., M. Eichenbaum, and S. Rebelo (2005): "Large Devaluations and the Real Exchange Rate," Journal of Political Economy, 113, 742-784.

(2007): "Modeling Exchange Rate Passthrough after Large Devaluations," Journal of Monetary Economics, 54, 346-368.

Burstein, A. T., J. C. Neves, and S. Rebelo (2003): "Distribution Costs and Real Exchange Rate Dynamics during Exchange-Rate-Based Stabilizations," Journal of Monetary Economics, 50, 1189-1214.

Campa, J. M. and L. S. Goldberg (2005): "Exchange Rate Pass-Through into Import Prices," The Review of Economics and Statistics, 87, 679-690.

Chatterjee, A., R. Dix-Carneiro, and J. Vichyanond (2011): "Multi-Product Firms and Exchange Rate Fluctuations," Working paper, University of Maryland.

Chen, N., J. Imbs, And A. Scott (2009): "The Dynamics of Trade and Competition," Journal of International Economics, 77, 50-62.

Devereux, M. B., C. Engel, And P. E. StorgaArd (2004): "Endogenous exchange rate pass-through when nominal prices are set in advance," Journal of International Economics, 63, 263-291.

Dixit, A. K. And J. E. Stiglitz (1977): "Monopolistic Competition and Optimum Product Diversity," American Economic Review, 67, 297-308.

Dornbusch, R. (1987): "Exchange Rates and Prices," American Economic Review, 77, 93-106. 
Dotsey, M. And R. G. King (2005): "Implications of state-dependent pricing for dynamic macroeconomic models," Journal of Monetary Economics, 52, 213-242.

Feenstra, R. C. (1994): "New Product Varieties and the Measurement of International Prices," American Economic Review, 84, 157-77.

(1996): "U.S. Imports, 1972-1994: Data and Concordances," NBER Working Papers 5515, National Bureau of Economic Research, Inc.

Feenstra, R. C., J. E. Gagnon, And M. M. Knetter (1996): "Market Share and Exchange Rate Pass-Through in World Automobile Trade," Journal of International Economics, 40, 187207.

Feenstra, R. C., J. Romalis, And P. K. Schott (2002): "U.S. Imports, Exports, and Tariff Data, 1989-2001," NBER Working Papers 9387, National Bureau of Economic Research, Inc.

Fitzgerald, D. And S. Haller (2010): "Exchange Rates and Producer Prices: Evidence from Micro-Data," Working paper, Stanford University.

Garetto, S. (2012): “"Firms' Heterogeneity and Incomplete Pass-Through", Working paper, Boston University.

Glick, R. And K. Rogoff (1995): "Global versus country-specific productivity shocks and the current account," Journal of Monetary Economics, 35, 159-192.

Goldberg, L. S. And J. M. Campa (2010): "The Sensitivity of the CPI to Exchange Rates: Distribution Margins, Imported Inputs, and Trade Exposure," The Review of Economics and Statistics, 92, 392-407.

Goldberg, L. S. And C. Tille (2009): "Micro, Macro, and Strategic Forces in International Trade Invoicing," Staff Reports 405, Federal Reserve Bank of New York.

GoldberG, P. K. And R. Hellerstein (2012): "A Structural Approach to Identifying the Sources of Local-Currency Price Stability," Forthcoming, Review of Economic Studies.

Goldberg, P. K. and F. Verboven (2001): "The Evolution of Price Dispersion in the European Car Market," Review of Economic Studies, 68, 811-48.

(2005): "Market integration and convergence to the Law of One Price: evidence from the European car market," Journal of International Economics, 65, 49-73.

Gopinath, G. And O. Itskhoki (2010): "Frequency of Price Adjustment and Pass-Through," The Quarterly Journal of Economics, 125, 675-727.

(2011): "In Search of Real Rigidities," in NBER Macroconomics Annual 2010, Volume 25, National Bureau of Economic Research, Inc, NBER Chapters, 261-309.

Gopinath, G., O. Itskhoki, And R. Rigobon (2010): "Currency Choice and Exchange Rate Pass-Through," American Economic Review, 100, 304-36.

Gopinath, G. and R. Rigobon (2008): "Sticky Borders," Quarterly Journal of Economics, 123, $531-575$. 
Gust, C., S. Leduc, And N. Sheets (2009): "The adjustment of global external balances: Does partial exchange-rate pass-through to trade prices matter?" Journal of International Economics, $79,173-185$.

Gust, C., S. Leduc, And R. Vigfusson (2010): "Trade integration, competition, and the decline in exchange-rate pass-through," Journal of Monetary Economics, 57, 309-324.

Hallak, J. C. And P. K. Schott (2011): "Estimating Cross-Country Differences in Product Quality," The Quarterly Journal of Economics, 126, 417-474.

Hellerstein, R. (2008): "Who bears the cost of a change in the exchange rate? Pass-through accounting for the case of beer," Journal of International Economics, 76, 14-32.

Johnson, R. (2012): "Trade and Prices with Heterogeneous Firms," Journal of International Economics, 81.

Khandelwal, A. (2010): "The Long and Short (of) Quality Ladders," Review of Economic Studies, 77, 1450-1476.

Kimball, M. S. (1995): "The Quantitative Analytics of the Basic Neomonetarist Model," Journal of Money, Credit and Banking, 27, 1241-77.

Knetter, M. M. (1989): "Price Discrimination by U.S. and German Exporters," American Economic Review, 79, 198-210.

(1992): "International Comparisons of Pricing-to-Market Behavior," NBER Working Papers 4098, National Bureau of Economic Research, Inc.

Krugman, P. (1986): "Pricing to Market when the Exchange Rate Changes," NBER Working Papers 1926, National Bureau of Economic Research, Inc.

LANDry, A. (2011): "Discussion of "How do Exporters React to Different Exchange Rate Shocks?" Discussion, Price Dynamics Conference of the Milton Friedman Institute (University of Chicago), February.

Loretan, M. (2005): "Indexes of the foreign exchange value of the dollar," Federal Reserve Bulletin, 1-8.

Manova, K. And Z. Zhang (2012): "Export Prices across Firms and Destinations," Quarterly Journal of Economics, 127.

Melitz, M. J. And G. I. P. Ottaviano (2008): "Market Size, Trade, and Productivity," Review of Economic Studies, 75, 295-316.

Michael, P., A. R. Nobay, And D. A. Peel (1997): "Transactions Costs and Nonlinear Adjustment in Real Exchange Rates: An Empirical Investigation," Journal of Political Economy, $105,862-79$.

Nakamura, E. And J. Steinsson (2008a): "Five Facts about Prices: A Reevaluation of Menu Cost Models," The Quarterly Journal of Economics, 123, 1415-1464. 
(2008b): "Five Facts about Prices: A Reevaluation of Menu Cost Models," Quarterly Journal of Economics, 123, 1415-1464.

(2012): "Lost in Transit: Product Replacement Bias and Pricing to Market," Forthcoming, American Economic Reviewoming, American Economic Review.

Nakamura, E. And D. Zerom (2010): “Accounting for Incomplete Pass-Through," Review of Economic Studies, 77, 1192-1230.

Neiman, B. (2010): "Stickiness, Synchronization and Passthrough in Intrafirm Trade Prices," Journal of Monetary Economics, 57, 295-308.

Pennings, S. (2012): "Pass-Through of Competitors' Exchange Rates," Working paper, NYU.

RAUCH, J. E. (1999): "Networks versus markets in international trade," Journal of International Economics, 48, 7-35.

Verboven, F. (1996): "International Price Discrimination in the European Car Market," $\underline{\text { RAND }}$ Journal of Economics, 27, 240-268.

YAnG, J. (1997): "Exchange Rate Pass-Through In U.S. Manufacturing Industries," The Review of Economics and Statistics, 79, 95-104. 


\section{$7 \quad$ Figures and Tables}

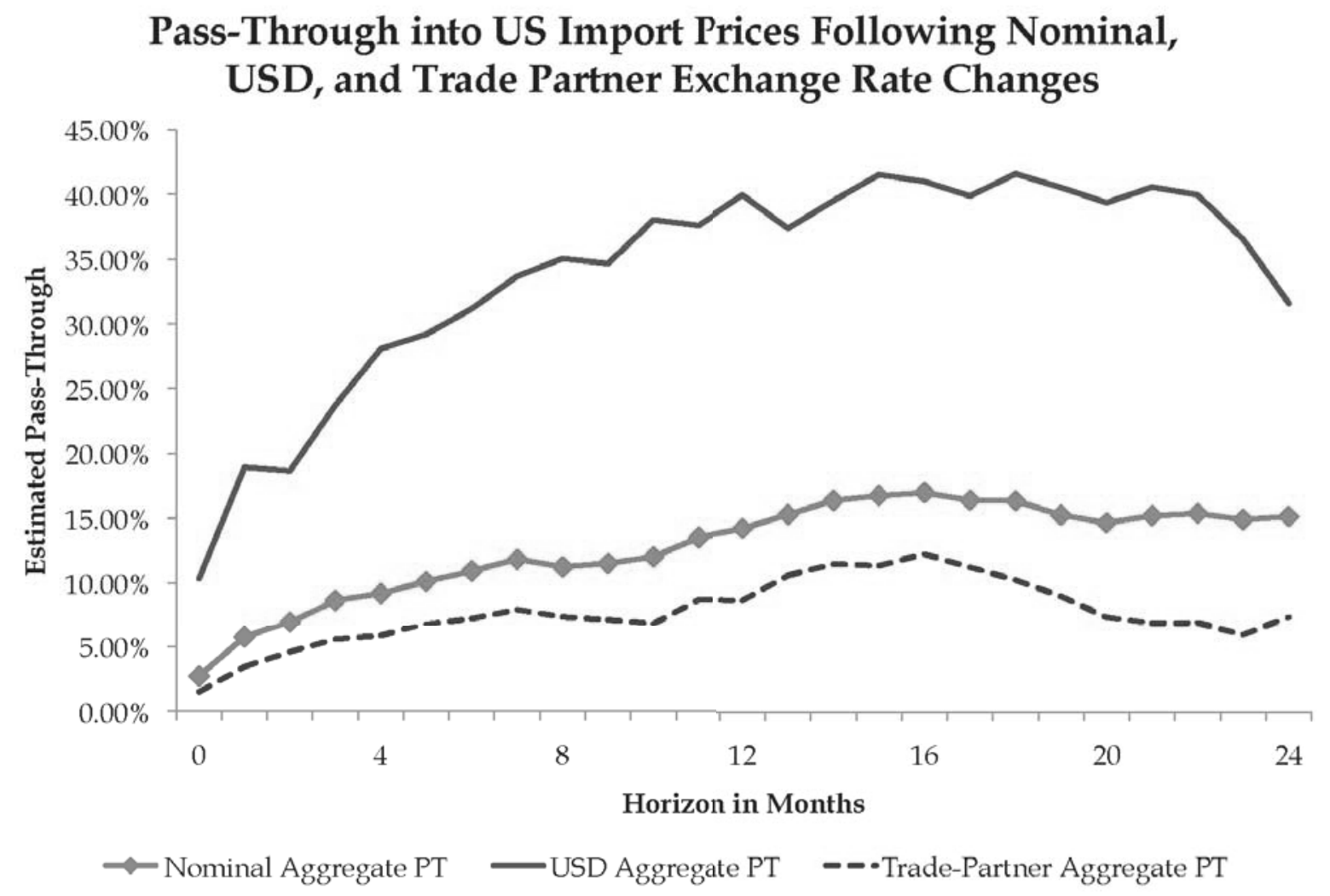

Figure 1: Pass-Through of Different Exchange Measures into US Import Prices

The figure shows estimates from the following specification: $\Delta p_{i, c, t}=\alpha_{c}+\sum_{j=1}^{n} \beta_{j} \Delta e_{c, t-j+1}+$ $\sum_{j=1}^{n} \gamma_{j}^{T P} \Delta \pi_{c, t-j+1}^{T P}+\epsilon_{i, c, t}$ where $i$ indexes goods, $c$ trade partners, $\alpha_{c}$ is a country fixed effect, $n$ measures the length of the pass-through horizon and varies from 1 to 25 , and $\Delta e_{c, t-j+1}$ is the change in either the log of the nominal, USD, or TPC exchange rate. For details of the exchange rate decomposition, see the discussion in the text. $\Delta p_{i, c, t}$ is the observed monthly log price change, and $\Delta \pi_{c, t-j+1}^{T P}$ is the monthly inflation rate in the foreign country using the consumer price index. The figure shows the $n$-month pass-through rates of each exchange rate measure, summing the coefficients up to the respective horizon. 


\section{Pass-Through under Joint Estimation (With 95\% C.I.)}

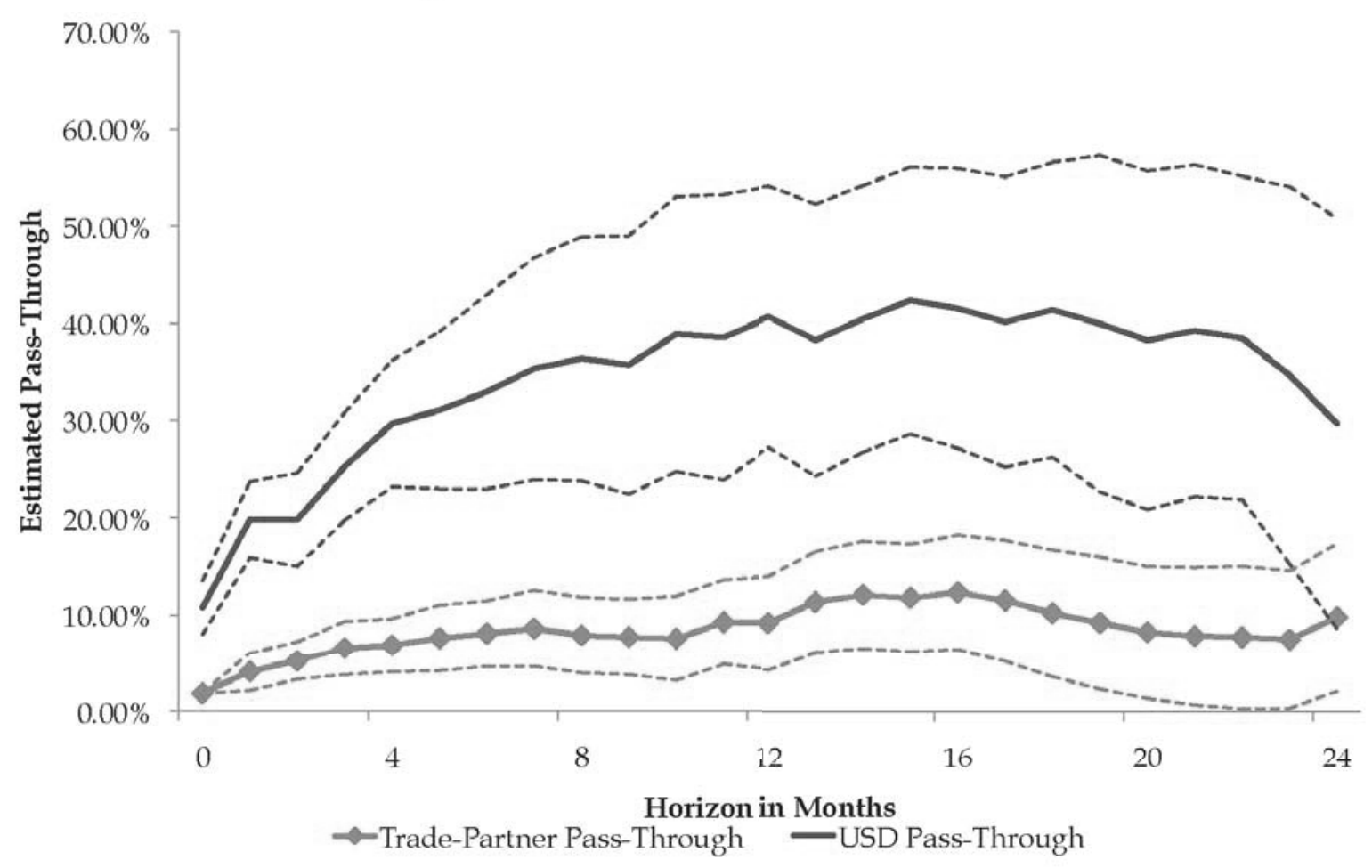

Figure 2: Jointly Estimated Pass-Through of USD and Trade-Partner Exchange Rate Changes into US Import Prices

The figure shows estimates from the following specification: $\Delta p_{i, c, t}=\alpha_{c}+$ $\sum_{j=1}^{n} \beta_{j}^{U S D} \Delta U S D_{R O W-c, t-j+1}+\sum_{j=1}^{n} \beta_{j}^{T P C} \Delta T P C_{c, t-j+1}+\sum_{j=1}^{n} \gamma_{j} \Delta \pi_{c, t-j+1}^{T P}+\epsilon_{i, c, t}$ where $\triangle T P C_{c, t-j+1}$ corresponds to TPC movements and $\triangle U S D_{R O W-c, t-j+1}$ to the USD movements of the exchange rate of country $c, i$ indexes goods, $\alpha_{c}$ is a country fixed effect, and $n$ measures the length of the pass-through horizon and varies from 1 to 25 . For details of the exchange rate decomposition, see the discussion in the text. $\Delta p_{i, c, t}$ is the observed monthly log price change, and $\Delta \pi_{c, t-j+1}^{T P}$ is the monthly inflation rate in the foreign country using the consumer price index. The figure shows the $n$-month pass-through rates of each exchange rate measure, summing the coefficients up to the respective horizon. 


\section{Sectoral TP Import Share and TPC Pass-Through}

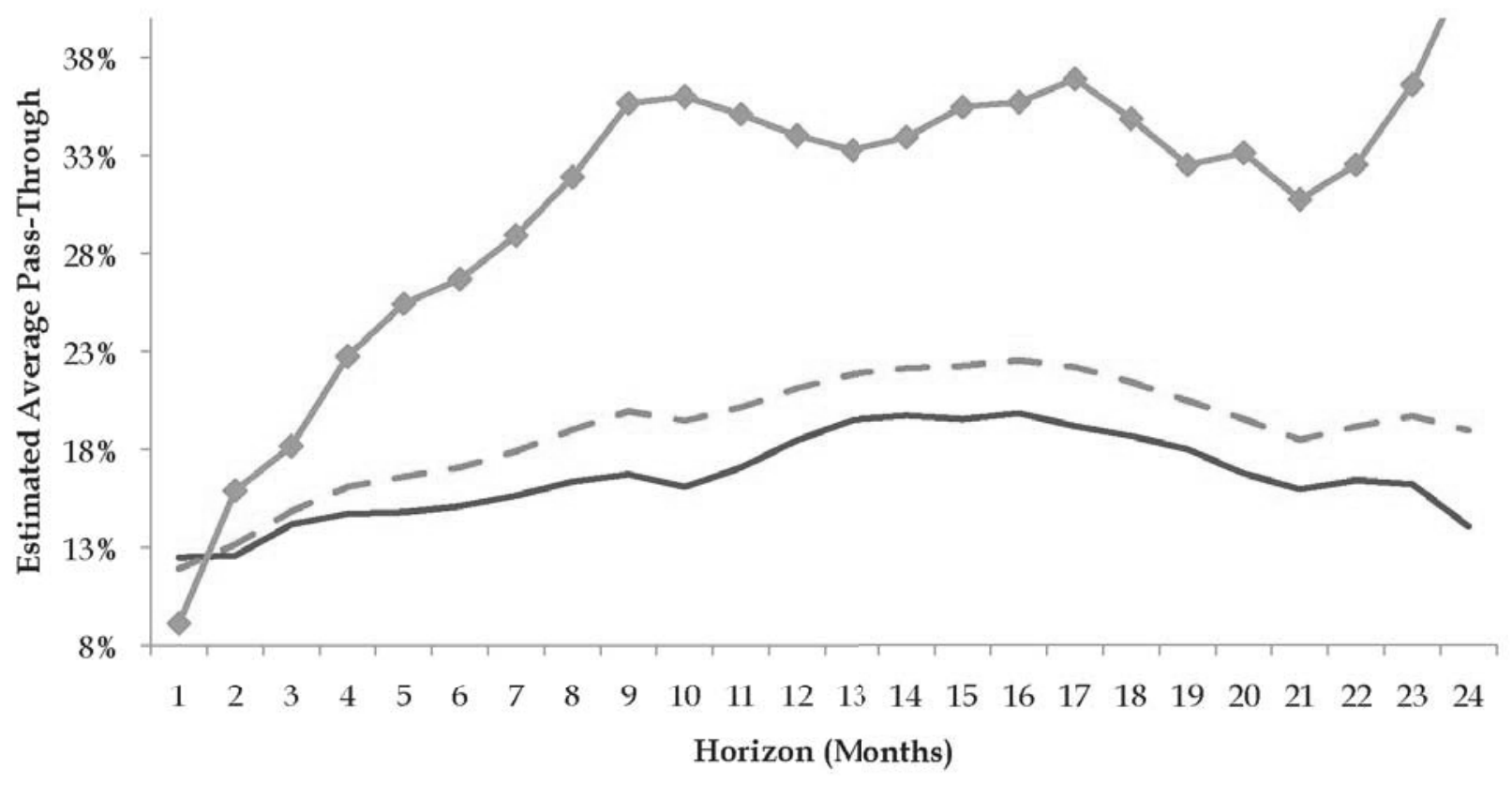

- Pass-Through of TP with $0 \%$ Import Share

- -Pass-Through of TP with Mean Import Share

$\leadsto$ Pass-Through of TP with 100\% Import Share

Figure 3: Pass-Through and Trade-Partner Import Share

The figures shows the response to TPC movements as a function of market shares of the respective importers, estimated from the following specification: $\Delta p_{i, c, k, t}=\alpha_{c}+\sum_{j=1}^{n} \beta_{j} \Delta T P C_{c, t-j+1}+$ $\sum_{j=1}^{n} \gamma_{j} m_{c, k} \Delta T P C_{c, t-j+1}+m_{c, k}+\epsilon_{i, c, k, t}$ where $i$ denotes a good, $\alpha_{c}$ is a country fixed effect, $k$ a sector, $n$ varies from 1 to $25, \Delta p_{i, c, k, t}$ is the observed monthly log price change, $\Delta T P C_{c, t-j+1}$ is the change in the trade-partner currency, and $m_{c, k}$ denotes the sector-specific import share measure of country $c$ in a given six-digit NAICS sector $k$. The figure shows the $n$-month pass-through rates of each exchange rate measure, summing up to the respective horizon the coefficients $\beta_{j}$ and $\gamma_{j} * m_{c, k}$ for near-zero, average and $100 \%$ market shares. For details of the construction of the TPC exchange rate measure, see the discussion in the text. 


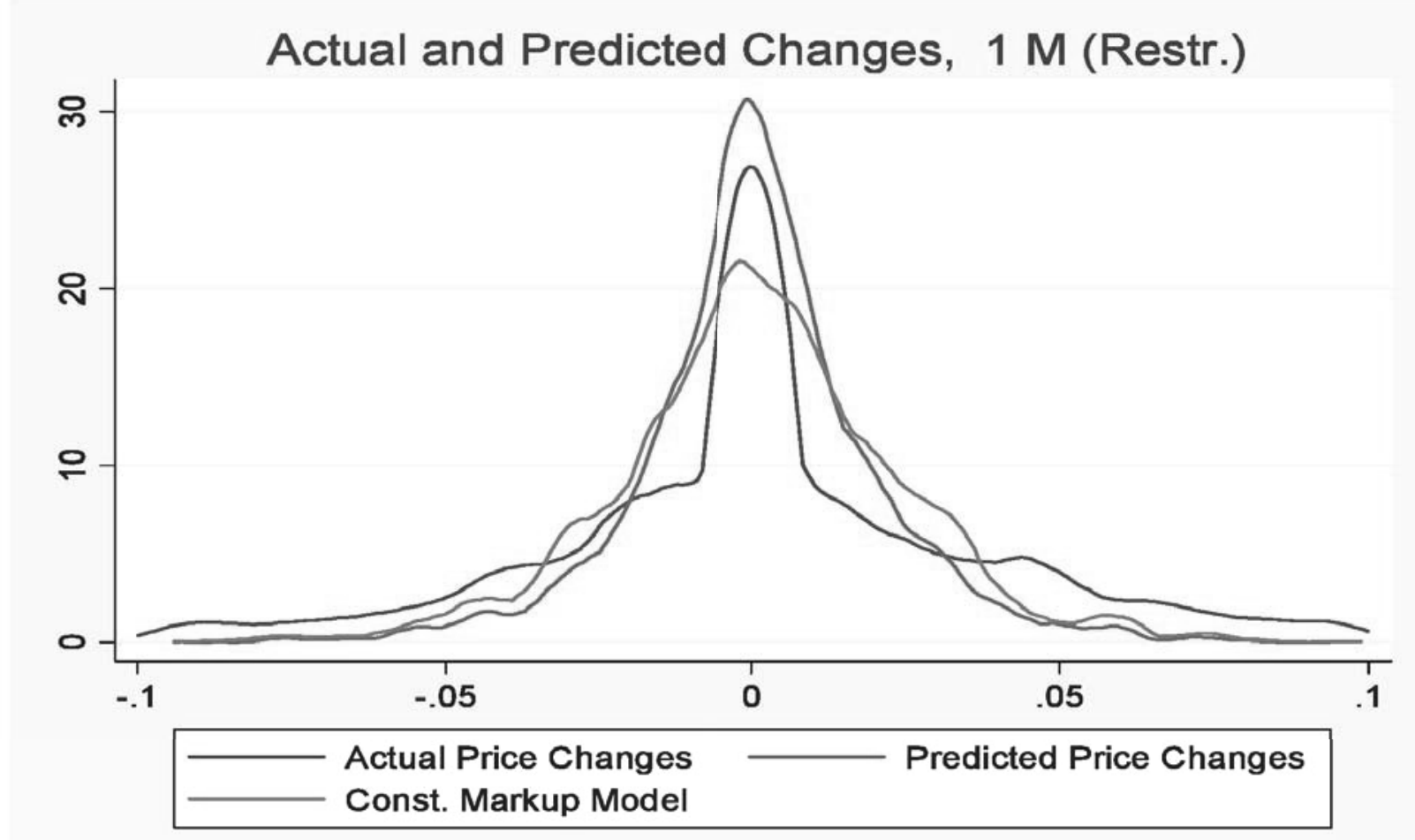

Figure 4: Kernel Density of Actual and Predicted Price Changes and Benchmark

The figure shows the distribution of observed log price changes and log price changes predicted by our model as described in Section 4.1 in the text. As a benchmark, we also show log price changes generated by a constant mark-up model. Price changes are monthly log price differences, and the distribution is truncated above $10 \%$ and below $-10 \%$. 


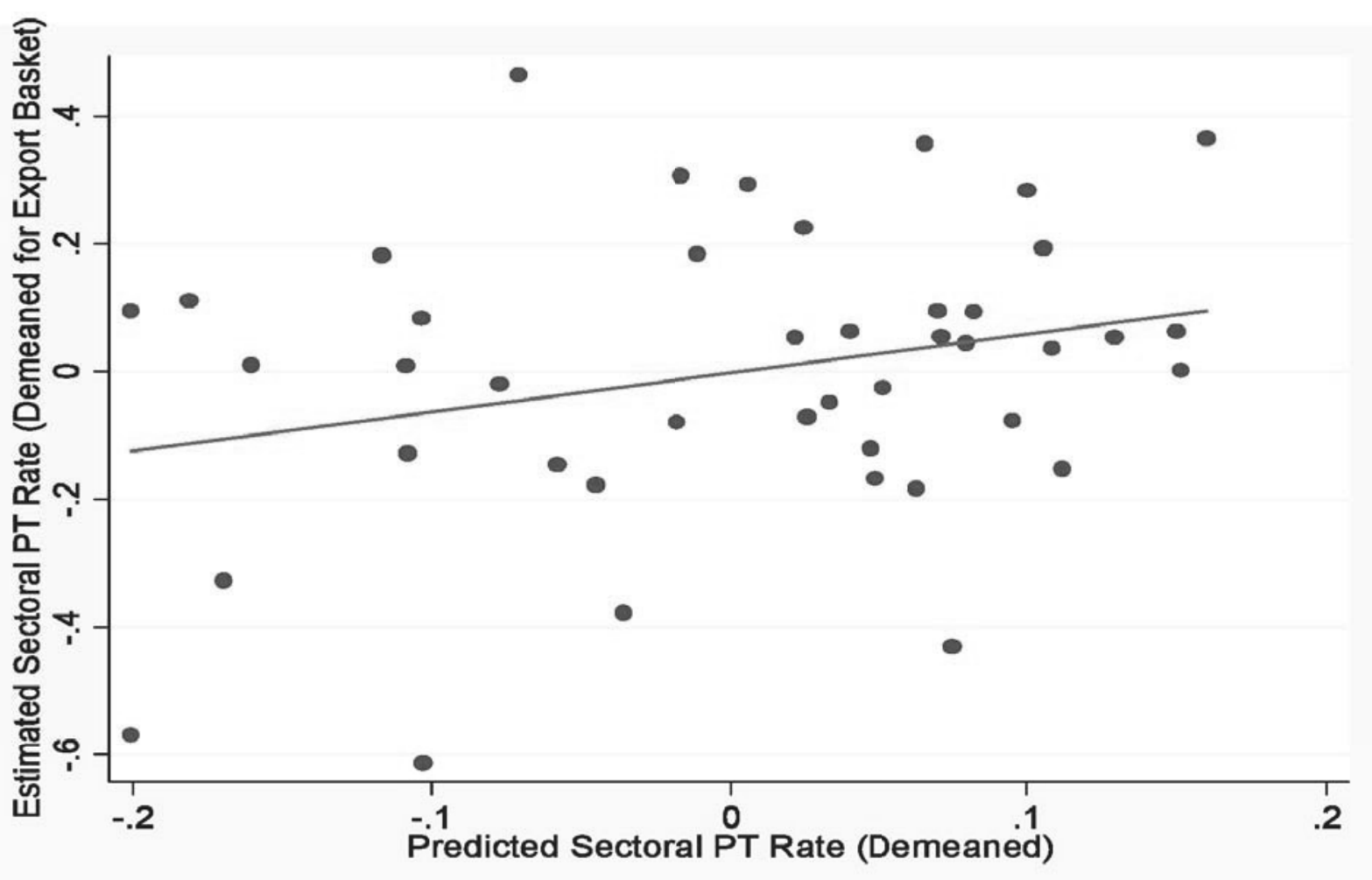

Figure 5: Estimated and Predicted TPC Pass-Through, Sector-Trade Partner Pairs

The figure shows estimated and predicted pass-through rates, at the sector-TP level. Pass-through is estimated from the following specification: $\Delta p_{i, c, t}=\alpha_{c}+\sum_{j=1}^{n} \beta_{j}^{T P C} T P C_{c, t-j+1}+\epsilon_{i, c, t}$ where $i$ denotes a good, $\alpha_{c}$ is a country fixed effect, $k$ a sector defined at the NAICS2 level, $\Delta p_{i, c, t}$ is the observed monthly log price change, and $T P C_{c, t-j+1}$ the TPC movement. The figure shows the sum of estimated coefficients $\sum_{j=0}^{24} \beta_{j}$ for each sector-TP combination. For details of the construction of the exchange rate measures, see the discussion in the text. Predicted pass-through is the two-digit NAICS sectoral mean of pass-through predicted as in Section 4.1 in the text. 


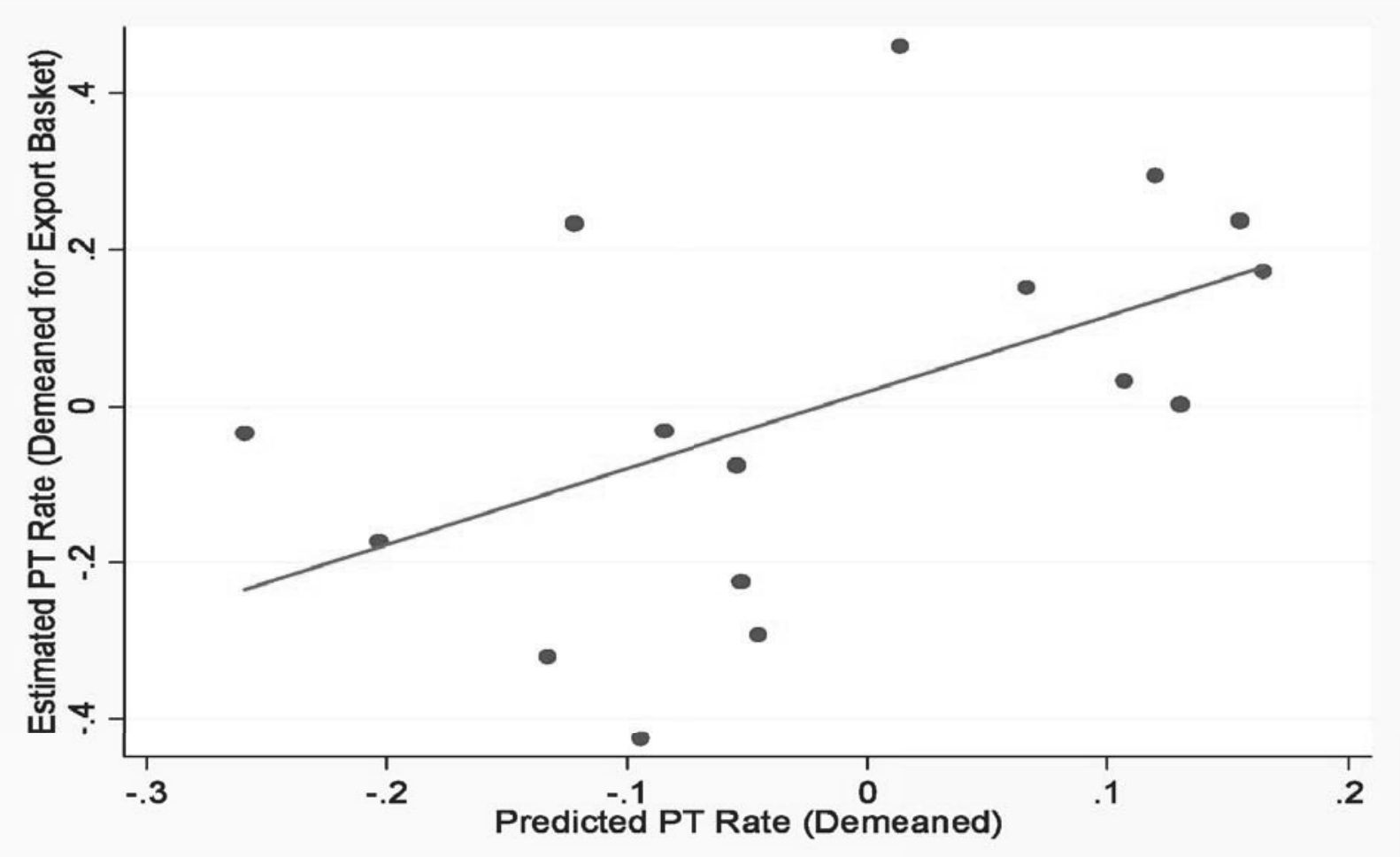

Figure 6: Estimated and Predicted Pass-Through, Country-Level

The figure shows estimated and predicted pass-through rates, aggregated to the country level. Passthrough is estimated from the following specification: $\Delta p_{i, c, t}=\alpha_{c}+\sum_{j=1}^{n} \beta_{j}^{T P C} \Delta T P C_{c, t-j+1}+\epsilon_{i, c, t}$ where $i$ denotes a good, $\alpha_{c}$ is a country fixed effect, $k$ a sector defined at the NAICS2 level, $\Delta p_{i, c, t}$ is the observed monthly log price change, and $\triangle T P C_{c, t-j+1}$ the TPC movement. The figure shows the sum of estimated coefficients $\sum_{j=0}^{24} \beta_{j}$ averaged over sectors for each country. For details of the construction of the exchange rate measures, see the discussion in the text. Predicted pass-through is the two-digit NAICS sectoral mean of pass-through predicted as described in Section 4.1 in the text, averaged over sectors for each country. 


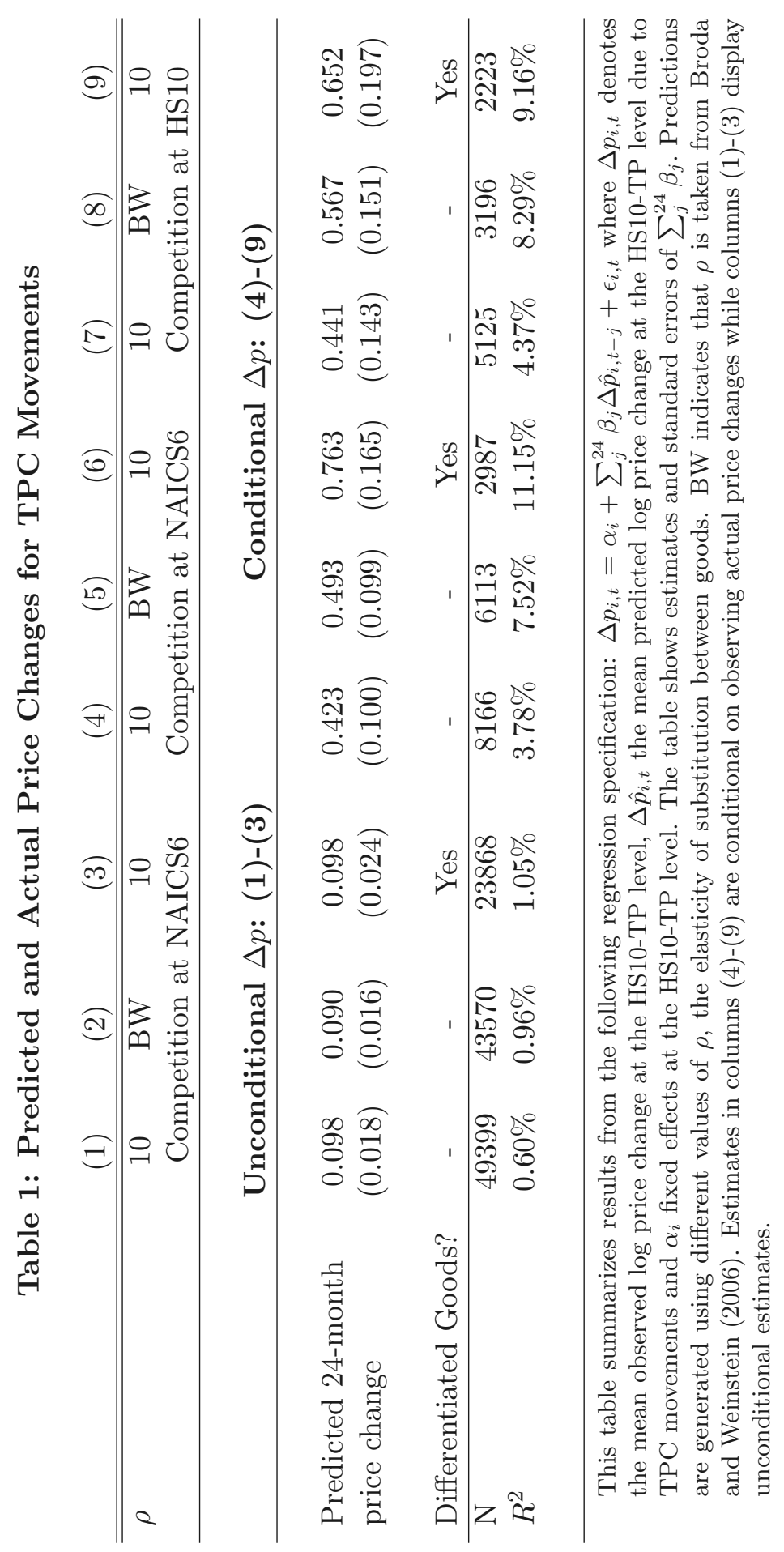




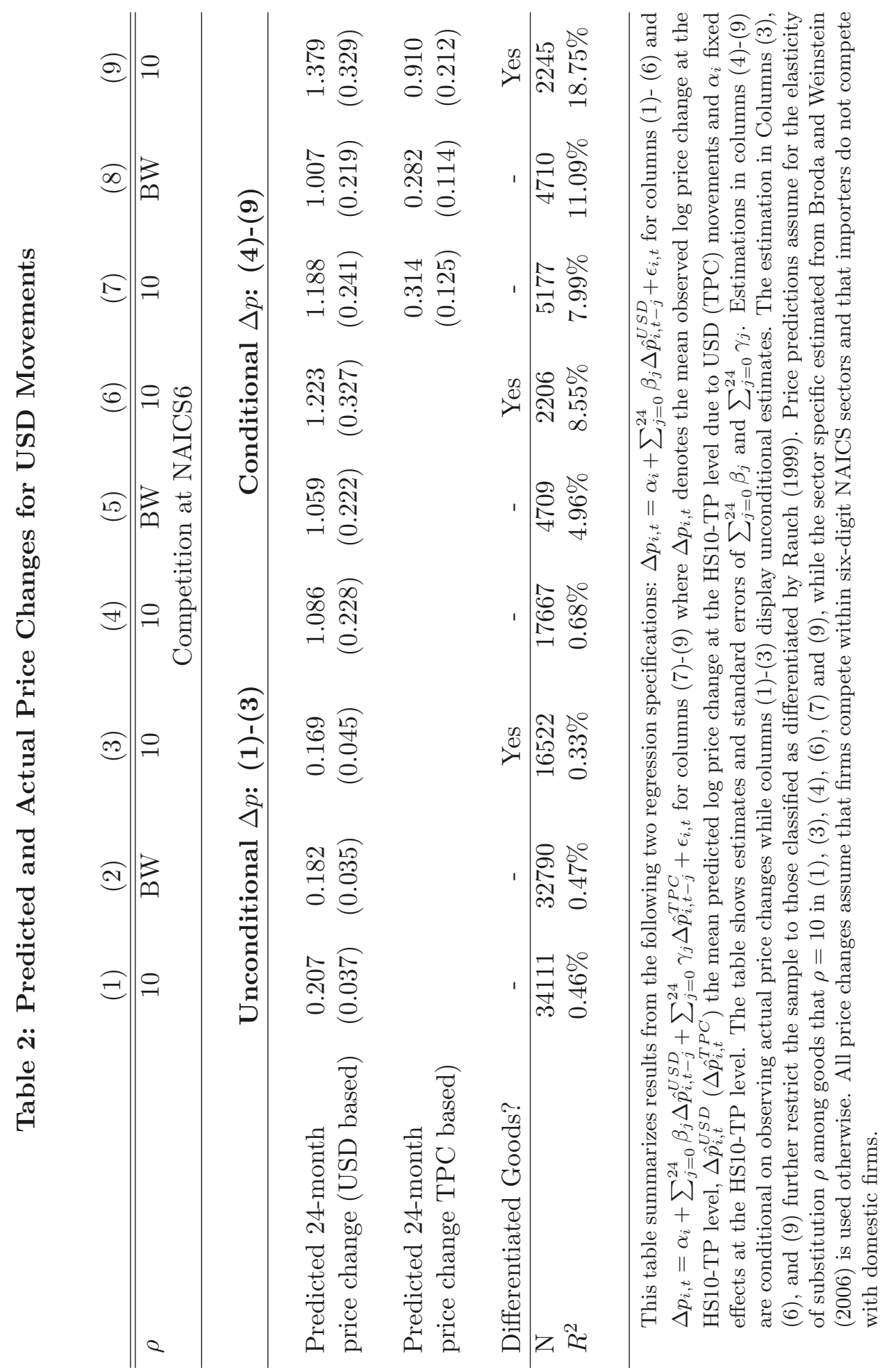


Table 3: Predicted and Actual Price Changes Accounting for Quality Heterogeneity

\begin{tabular}{ccccccccc} 
& $(1)$ & $(2)$ & $(3)$ & $(4)$ & $(5)$ & $(6)$ & $(7)$ & $(8)$ \\
\hline \hline$\rho$ & 10 & 10 & 10 & 10 & 10 \\
& & \multicolumn{7}{c}{ Competition at NAICS6 } \\
& & \multicolumn{1}{c}{10} & 10 & 10 \\
\hline
\end{tabular}

\section{Exact Market-Share Subsample Unconditional $\Delta p$ Conditional $\Delta p$}

\section{Simulated Productivity} Unconditional $\Delta p$ Conditional $\Delta p$

\begin{tabular}{|c|c|c|c|c|c|c|c|c|}
\hline $\begin{array}{l}\text { Predicted } 24 \text {-month } \\
\text { price change }\end{array}$ & $\begin{array}{c}0.062 \\
(0.031)\end{array}$ & $\begin{array}{l}0.096 \\
(0.046)\end{array}$ & $\begin{array}{c}0.721 \\
(0.213)\end{array}$ & $\begin{array}{l}1.552 \\
(0.341)\end{array}$ & $\begin{array}{c}0.106 \\
(0.023)\end{array}$ & $\begin{array}{c}0.092 \\
(0.028)\end{array}$ & $\begin{array}{c}0.562 \\
(0.131)\end{array}$ & $\begin{array}{c}0.722 \\
(0.173)\end{array}$ \\
\hline Differentiated Goods? & - & Yes & - & Yes & - & Yes & - & Yes \\
\hline $\mathrm{N}$ & 20364 & 9400 & 2574 & 967 & 34703 & 18826 & 5496 & 2455 \\
\hline$R^{2}$ & $0.61 \%$ & $1.28 \%$ & $10.39 \%$ & $31.11 \%$ & $0.77 \%$ & $1.06 \%$ & $5.08 \%$ & $10.57 \%$ \\
\hline
\end{tabular}




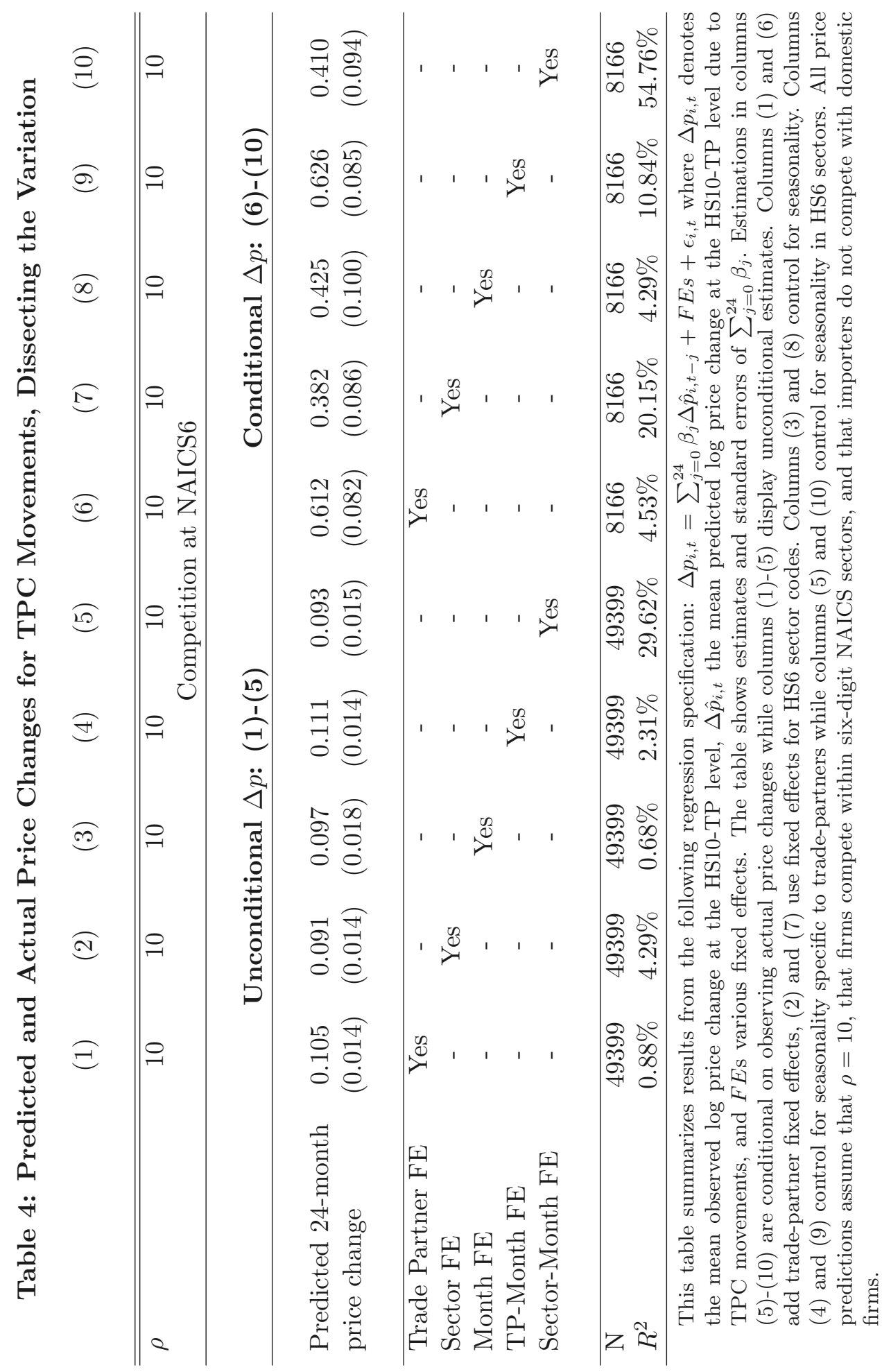




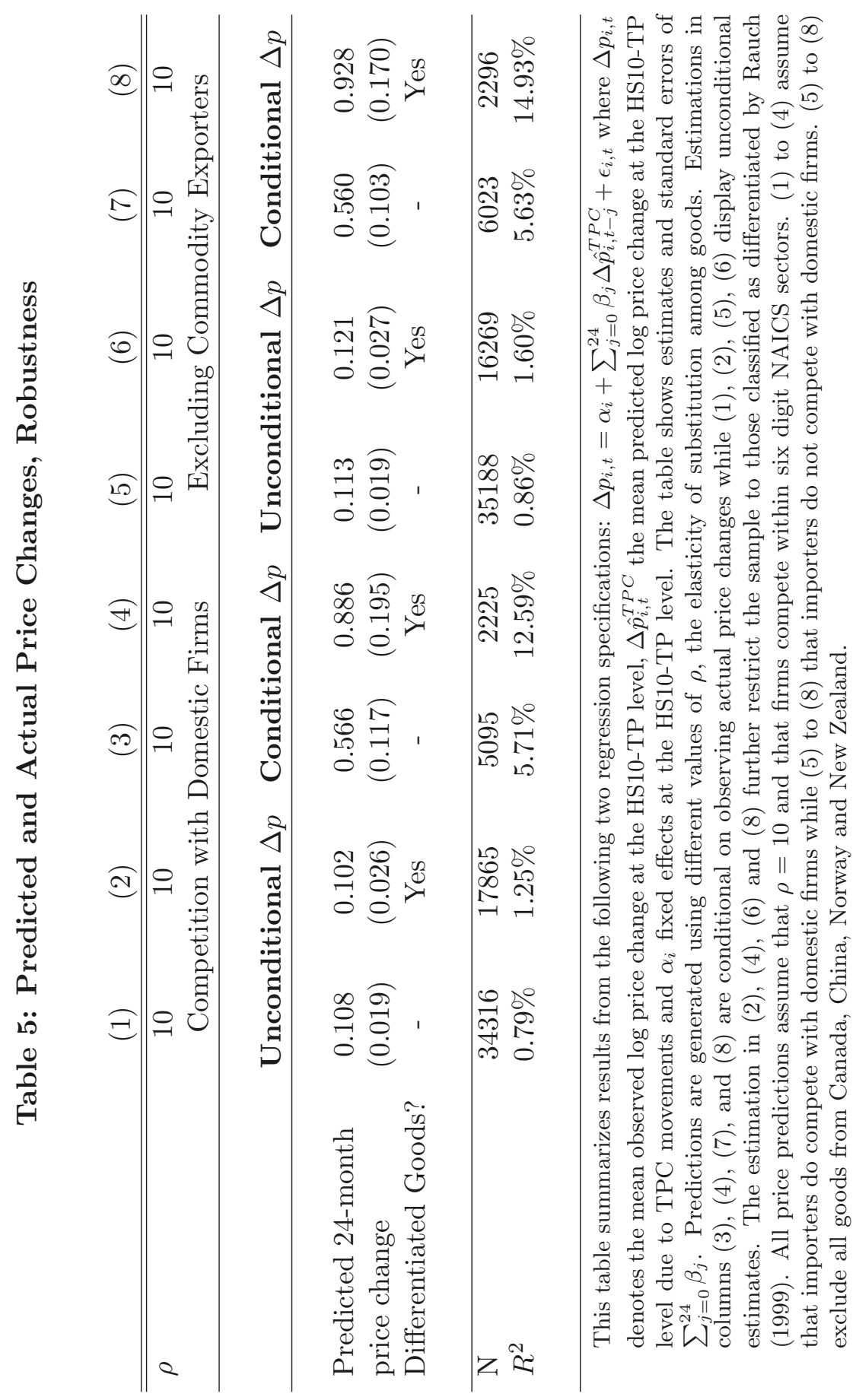




\section{A APPENDIX: Proofs of Proposition 1 and 2}

\section{A.1 Proposition 1}

Proof. The change in the sectoral price level $\widehat{P}_{k}$ can be solved for by acknowledging that $\widehat{P}_{k}$ itself is the sum of all individual prices changes (10) weighted by the firm's market share $s_{j, k}$ :

$$
\widehat{P}_{k}=\sum_{j \in N_{k}} s_{j} \gamma_{j, k} \widehat{P}_{k}+\sum_{j \in N_{k}} s_{j} \alpha_{j, k} \widehat{w}_{j, k}
$$

That is, the change in the general price level $\widehat{P}_{k}$ depends on the total first round effect of how each firm responds to changing costs (reflected by the second summation in (21)) and on second-round effects: all prices depend on the general price level, which multiplies the first-round effect. Then, solving for the equilibrium price yields

$$
\widehat{P}_{k}=\underbrace{\sum_{j \in N_{k}} s_{j} \alpha_{j, k} \widehat{w}_{j, k}}_{\text {1st Round Total Direct Cost Effect }} / \underbrace{\left(1-\sum_{j \in N_{k}} s_{j} \gamma_{j, k}\right)}_{\text {Higher Round Multiplier }} .
$$

Substitution into (10) directly gives the rate of price changes as a function of the fundamental cost changes.

The solution to the recursive system of individual prices (10) is surprisingly simple. The reason for this simplicity is that the price of any firm $n$ reacts linearly to the linear composition of other prices $\widehat{P}_{k}=\sum_{j \in N} s_{j} \widehat{P}_{j, k}$ as the preferences are additively linear within nest $k$.

\section{A.2 Proposition 2}

Proof. First, note that the change of the general price index is simply $\widehat{P}_{k}=n_{U S} \widehat{P}_{U S}+n_{T P} \widehat{P}_{T P}+$ $n_{R O W} \widehat{P}_{R O W}$, and that the price of a firm from country $c \in\{U S, T P, R O W\}$ is equal to

$$
\widehat{P}_{c, k}=\bar{\Gamma}\left(\widehat{P}_{k}-\widehat{P}_{c, k}\right)+\widehat{w}_{c, k}
$$

Solving the system of three pricing equations (11) for the case of equal-sized firms yields the following optimal price response for a firm originating from country n:

$$
\widehat{P}_{n, k}=\overline{\alpha \gamma} \frac{\sum_{j \epsilon N_{k}} s_{j} \Delta e_{c, t}}{1-\bar{\gamma}}+\bar{\alpha} \Delta e_{c, t}+\widetilde{\varepsilon}_{n, k} .
$$

Then, remembering our definitions of the exchange rate decomposition in (2), a TPC movement of a trade partner TP implies that $\triangle U S D_{R O W-c, t}=0$ and $\Delta T P C_{c, t} \neq 0$. To relate this to our empirical approach of identifying cost pass-through, we write $\widehat{w}_{U S D}=\Delta U S D_{R O W-c, t}$ and $\widehat{w}_{T P C}^{\prime} \equiv \triangle T P C_{c, t}-\Delta U S D_{R O W-c, t}$ yielding the TPC price change for the case of equally sized firms:

$$
\widehat{P}_{T P C, c}=\bar{\gamma} \underbrace{\frac{1}{1-\bar{\gamma}} n_{T P} \bar{\alpha} \Delta T P C_{c, t}}_{\text {Effect of TPC on } \widehat{P}_{k}}+\underbrace{\bar{\alpha} \Delta T P C_{c, t}}_{\text {Direct Cost Effect }}+\widetilde{\varepsilon}_{n, k} .
$$


where TPC pass-through is given by the sum of coefficients multiplying $\triangle T P C_{c, t}$.

Second, remembering the price response to broad USD shock defined as in Equation (1), as well as the fact that all prices are denominated in dollars so that the wage change of US firms is equal to 0 by definition, a USD movement implies that $\Delta U S D_{R O W-c, t}=\Delta T P C_{c, t}$, while

$$
\widehat{P}_{U S D, c}=\bar{\gamma} \underbrace{\frac{1}{1-\bar{\gamma}}\left(n_{R O W}+n_{T P}\right) \bar{\alpha} \Delta U S D_{R O W-c, t}}_{\text {Effect of USD on } \widehat{P}_{k}}+\underbrace{\bar{\alpha} \Delta U S D_{R O W-c, t}}_{\text {DirectCost Effect }}+\widetilde{\varepsilon}_{n, k} .
$$

where USD pass-through is again given by the sum of coefficients multiplying $\hat{\omega}_{U S D}$.

The remainder of the proofs follows directly from taking derivatives of the pass-through expressions. For item 2. in the proposition, note that $1-n_{U S}=n_{T P}+n_{R O W}$.

\section{B APPENDIX: Data description}

We use exchange rates and inflation data from the IMF's International Financial Statistics database, and, most importantly, import prices at the good level from the BLS. The latter micro price data have been the topic of intense study since the original analysis of this dataset by Gopinath and Rigobon (2008).

We refer the reader to Gopinath and Rigobon (2008) for a detailed description of the US import price micro data. In this paper, we analyze the years from 1994 through 2005 . We apply our analysis to the following countries: Austria, Canada, China, Denmark, Czech Republic, Finland, France, Germany, Greece, Hungary, Ireland, Italy, Japan, Mexico, Netherlands, New Zealand, Norway, Portugal, Singapore, South Korea, Spain, Sweden, Switzerland, Taiwan, United Kingdom.

In manipulating the data, we follow the main steps taken in Gopinath and Rigobon (2008). In particular, we drop net price data which are flagged by the BLS as not usable, not index usable or for which a price has been estimated. There are 771872 usable prices in our sample. In addition, we pull forward a last observed price when a price is missing as in Nakamura and Steinsson (2012). We also disregard an entire price series if more than $10 \%$ of prices of a series have been flagged as price records with no trade. All of our prices are market price transactions invoiced in USD. ${ }^{22}$

To construct trade partner market shares, we use bilateral US import data from the US Census, disaggregated at either the six-digit Harmonized System (HS) or the six-digit North American Industry Classification System (NAICS). To construct measures of the openness of a sector, we require data on domestic sales in addition to imports. We use data on the shipments of domestic firms recorded in the Annual Survey of Manufacturers, which is available from the US census at the six-digit NAICS level.

\section{APPENDIX: Additional Figures and Tables}

Is the fact that TPC currency is low driven by specific trade partners? In Table C.2, we estimate the PT rate jointly following USD and TPC movements for each of the countries in our sample separately and at the 6 and 12-months horizons. These estimations unveil a large degree in

\footnotetext{
${ }^{22}$ As Gopinath and Rigobon (2008) have documented, almost all US imports are priced in USD. For example, $93.4 \%$ of all import prices are in USD in 2004. Neiman (2010) explicitly studies the behavior of intra-firm prices which account for approximately $40 \%$ of the data.
} 
heterogeneity, with the TPC PT rate varying from $17 \%$ to $68 \%$ and the USD PT rate varying from $16 \%$ to $90 \%$. However, it is both true that the median and the mean TPC rate are statistically lower than the mean and median of the USD rate. Moreover, it is also true that for 16 out of the 23 trade partners, TPC pass-through is estimated to be higher than USD pass-through.

Is the difference in PT rates following TPC and USD movements driven by specific sectors? We next estimate disaggregate pass-through regressions within 3-digit NAICS sectors (we do not have enough data points for estimating PT rates within finer disaggregations). Figure C.1 displays the PT rates at the 1-24 month(s) horizons for two selected industries (NAICS 314 "Textile product mills", blue lines and 325 "Chemical Manufacturing", red lines). In both sectors, the TPC PT rate (dashed lines) is markedly below the USD PT rate (solid line).

To run the same robustness check for all 3-digit NAICS industries, Figure C.2 next presents a scatter plot relating the USD PT rate to the TPC PT rate. In this diagram, the vertical axis displays the estimated sector-specific USD PT rate. The horizontal axis presents the TPC PT rate. In Figure C.2, each datapoint then displays the TPC and the USD PT rate in one sector and at the 12-month time horizon. Figure C.2 also plots the 45 degree line. The majority of observations are above this line, hence indicating that USD PT is indeed higher one average than the TPC PT rate. Also a fitted line is estimated above the 45 degree line.

These robustness checks confirm that pass-through of broad USD movements is larger than trade-partner or nominal exchange rate pass-through also at the country and three-digit NAICS level. Broad USD movements are passed through into U.S. import prices at a substantially higher rate than trade-partner movements.

\section{Table C.1: Nominal vs USD or Trade Partner Pass-Through Rates}

\begin{tabular}{l|ccccc} 
& $(1)$ & $(2)$ & $(3)$ & $(4)$ & $(5)$ \\
\hline & NOM & USD & TPC & USD & TPC \\
Sample: & $(1)-(3)$ All Observations, Single Estimation & $(4)-(5)$ Full sample, joint estimation \\
\hline \hline Horizon & \multicolumn{7}{c}{} \\
\hline 1 & $5.75 \%$ & $18.92 \%$ & $3.44 \%$ & $19.81 \%$ & $4.09 \%$ \\
3 & $8.63 \%$ & $23.72 \%$ & $5.58 \%$ & $25.28 \%$ & $6.55 \%$ \\
6 & $10.91 \%$ & $31.16 \%$ & $7.23 \%$ & $32.96 \%$ & $8.06 \%$ \\
12 & $14.18 \%$ & $39.94 \%$ & $8.63 \%$ & $40.69 \%$ & $9.16 \%$ \\
18 & $16.33 \%$ & $41.58 \%$ & $10.21 \%$ & $41.39 \%$ & $10.15 \%$ \\
24 & $15.11 \%$ & $31.59 \%$ & $7.34 \%$ & $29.67 \%$ & $9.73 \%$ \\
\hline
\end{tabular}

The table shows estimates of PT for nominal bilateral, TPC and USD movements, as shown in Figures 1 and 2. The estimated specification for (1)-(3) is $\Delta p_{i, c, t}=\alpha_{c}+\sum_{j=1}^{n} \beta_{j} \Delta e_{c, t-j+1}+\sum_{j=1}^{n} \gamma_{j}^{T P} \Delta \pi_{c, t-j+1}^{T P}+\epsilon_{i, c, t}$ where $i$ indexes goods, $c$ trade partners, $\alpha_{c}$ is a country fixed effect, $n$ measures the length of the pass-through horizon, and $\Delta e_{c, t-j+1}$ is the monthly change in either the log of the nominal, USD, or TPC exchange rate. Details of the exchange rate decomposition are in the discussion in the text. $\Delta \pi_{c, t-j+1}^{T P}$ is the monthly inflation rate in the foreign country using the consumer price index. The estimated specification for (4)-(5) is $\Delta p_{i, c, t}=\alpha_{c}+\sum_{j=1}^{n} \beta_{j}^{U S D} \Delta U S D_{R O W-c, t-j+1}+\sum_{j=1}^{n} \beta_{j}^{T P C} \Delta T P C_{c, t-j+1}+\sum_{j=1}^{n} \gamma_{j} \Delta \pi_{c, t-j+1}^{T P}+\epsilon_{i, c, t}$ where $\triangle T P C_{c, t-j+1}$ corresponds to TPC movements and $\triangle U S D_{R O W-c, t-j+1}$ to the USD movements of the exchange rate of country $c$. 
Table C.2: Trade-Partner and USD Exchange Rate Pass-Through by Country

\begin{tabular}{|c|c|c|c|c|}
\hline & TPC & USD & $\mathrm{TPC}$ & USD \\
\hline Country/Horizon & 6 months & \multicolumn{3}{|c|}{12 months } \\
\hline Canada & $16 \%$ & $37 \%$ & $32 \%$ & $54 \%$ \\
\hline Mexico & $2 \%$ & $18 \%$ & $5 \%$ & $-1 \%$ \\
\hline Sweden & $10 \%$ & $37 \%$ & $18 \%$ & $54 \%$ \\
\hline Norway & $16 \%$ & $61 \%$ & $20 \%$ & $63 \%$ \\
\hline Finland & $7 \%$ & $26 \%$ & $13 \%$ & $36 \%$ \\
\hline Denmark & $18 \%$ & $43 \%$ & $23 \%$ & $39 \%$ \\
\hline UK & $4 \%$ & $56 \%$ & $-44 \%$ & $75 \%$ \\
\hline Ireland & $1 \%$ & $-9 \%$ & $16 \%$ & $-9 \%$ \\
\hline Netherlands & $-4 \%$ & $87 \%$ & $14 \%$ & $90 \%$ \\
\hline France & $17 \%$ & $12 \%$ & $18 \%$ & $5 \%$ \\
\hline Germany & $51 \%$ & $31 \%$ & $56 \%$ & $34 \%$ \\
\hline Austria & $24 \%$ & $34 \%$ & $30 \%$ & $62 \%$ \\
\hline Czech & $8 \%$ & $17 \%$ & $10 \%$ & $77 \%$ \\
\hline Hungary & $-17 \%$ & $90 \%$ & $1 \%$ & $69 \%$ \\
\hline Switzerland & $56 \%$ & $52 \%$ & $59 \%$ & $52 \%$ \\
\hline China & $8 \%$ & $-16 \%$ & $24 \%$ & $-22 \%$ \\
\hline Portugal & $25 \%$ & $47 \%$ & $43 \%$ & $72 \%$ \\
\hline Italy & $27 \%$ & $32 \%$ & $37 \%$ & $36 \%$ \\
\hline Greece & $-1 \%$ & $10 \%$ & $7 \%$ & $21 \%$ \\
\hline Singapore & $68 \%$ & $20 \%$ & $53 \%$ & $36 \%$ \\
\hline Korea & $2 \%$ & $24 \%$ & $9 \%$ & $39 \%$ \\
\hline Japan & $29 \%$ & $4 \%$ & $46 \%$ & $-10 \%$ \\
\hline New Zealand & $21 \%$ & $55 \%$ & $10 \%$ & $53 \%$ \\
\hline Mean & $24 \%$ & $37 \%$ & $30 \%$ & $51 \%$ \\
\hline Median & $25 \%$ & $34 \%$ & $29 \%$ & $50 \%$ \\
\hline \multicolumn{5}{|c|}{$\begin{array}{l}\text { The table shows country-specific estimates of PT for } \\
\text { TPC and USD movements. The estimated specifi- } \\
\text { cation is } \Delta p_{i, c, t}=\sum_{j=1}^{n} \beta_{j}^{U S D} \Delta U S D_{R O W-c, t-j+1}+ \\
\sum_{j=1}^{n} \beta_{j}^{T P C} \Delta T P C_{c, t-j+1}+\sum_{j=1}^{n} \gamma_{j} \Delta \pi_{c, t-j+1}^{T P}+\epsilon_{i, c, t} \text { where } \\
i \text { indexes goods, } c \text { trade partners and } n \text { measures the length of } \\
\text { the pass-through horizon with } n \in(6,12) \text {. Details of the exchange } \\
\text { rate decomposition are in the discussion in the text. } \Delta p_{i, c, t} \text { is the } \\
\text { observed monthly log price change, and } \Delta \pi_{c, t-j+1}^{T P} \text { is the monthly } \\
\text { inflation rate in the foreign country using the consumer price } \\
\text { index. The table reports the sum of the estimated coefficients } \beta_{j}^{i}{ }_{j}^{i} \\
\text { at } 6 \text { and } 12 \text { month horizons for } i \in(U S D, T P C) \text {. }\end{array}$} \\
\hline
\end{tabular}




\section{Pass-Through of USD and TPC Movements for Two Selected Industries}

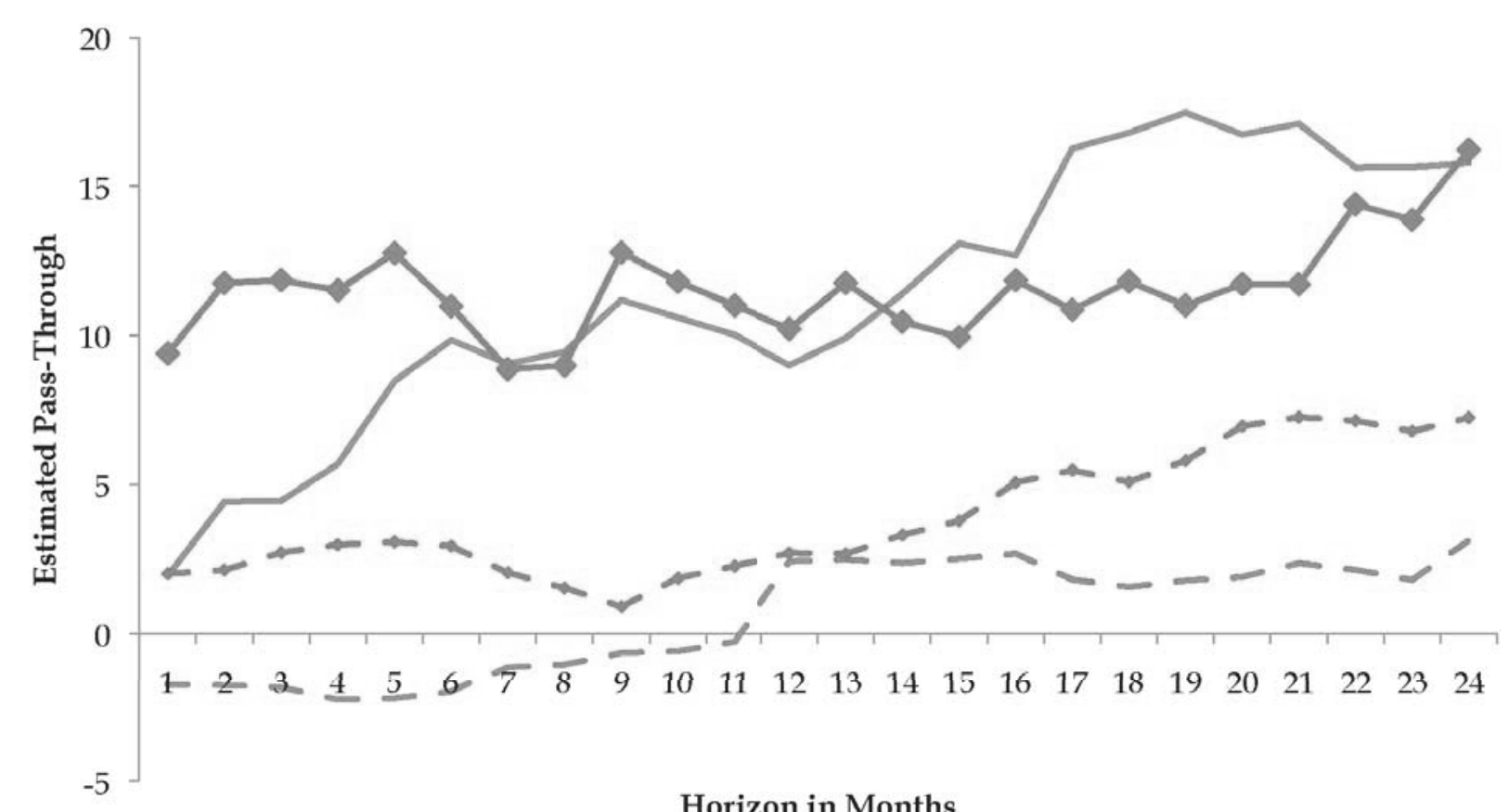

Horizon in Months

$$
--314 \text { TPC PT } \longrightarrow 314 \text { USD PT } \rightarrow-325 \text { TPC PT } \rightarrow 325 \text { USD PT }
$$

Figure C.1: Pass-Through for TP and USD Movements for NAICS Industries 314 and 325

The figures shows estimates of TPC and USD pass-through for two specific sectors from the following specification $\Delta p_{i, c, t}=\alpha_{c}+\sum_{j=1}^{n} \beta_{j}^{T P C} T P C_{c, t-j+1}+\sum_{j=1}^{n} \beta_{j}^{U S D} U S D_{c, t-j+1}+\epsilon_{i, c, t}$ where $i$ denotes a good, $\alpha_{c}$ is a country fixed effect, either 314 or $325, \Delta p_{i, c, t}$ is the observed monthly $\log$ price change, and $T P C_{c, t-j+1}$ and $U S D_{c, t-j+1}$ TP and USD movements. The figure shows the sum of the coefficients $\sum_{j=0}^{n} \beta_{j}$ estimated for each exchange rate measure and each sector at each horizon. For details of the construction of the exchange rate measures, see the discussion in the text. 


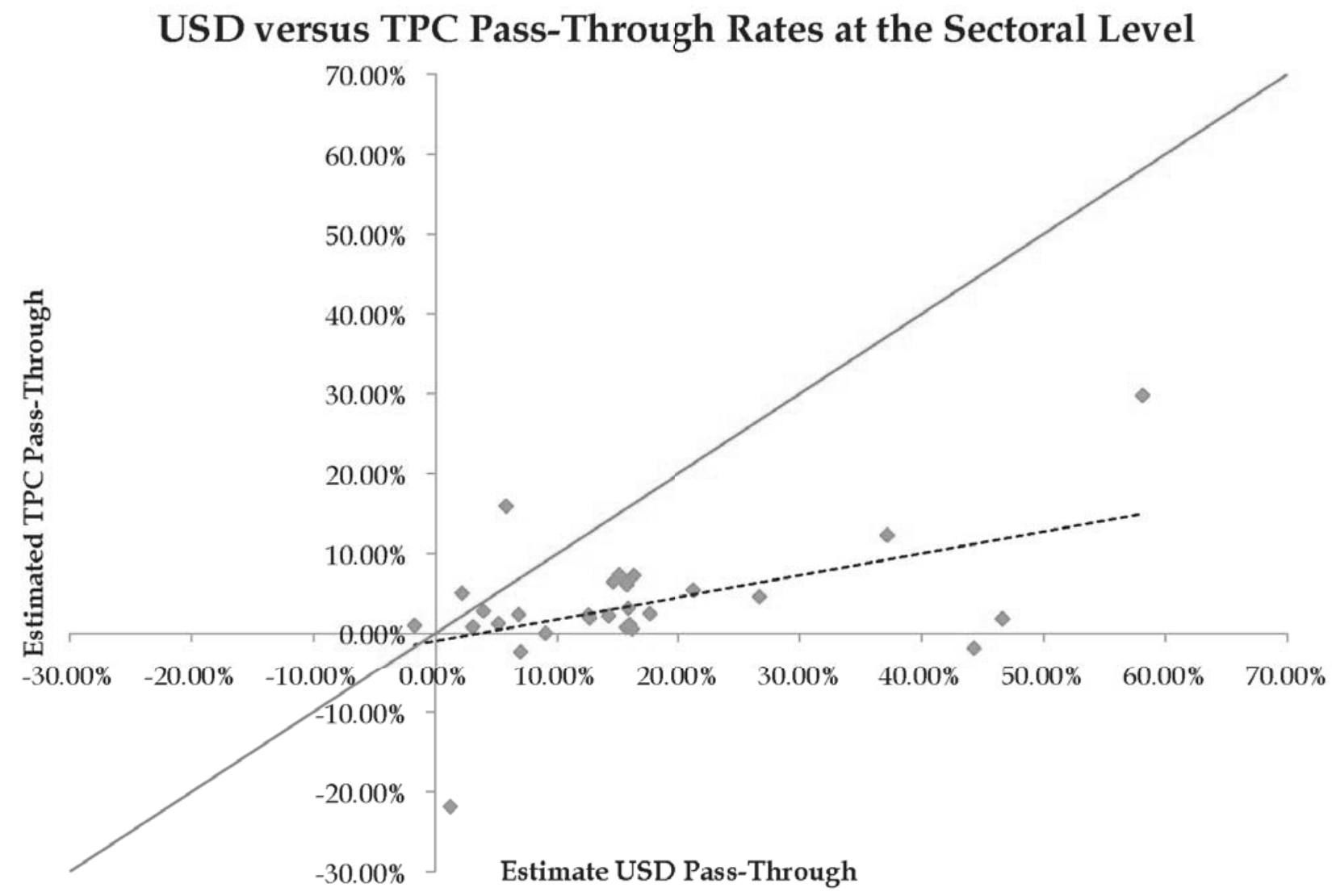

Figure C.2: USD versus TPC Pass-Through Rates at the Sectoral Level

The figures shows estimates of TPC and USD pass-through by sector from the following specification $\Delta p_{i, c, t}=\alpha_{c}+\sum_{j=1}^{24} \beta_{j} e_{c, t-j+1}+\epsilon_{i, c, t}$ where $i$ denotes a good, $\alpha_{c}$ is a country fixed effect, $\Delta p_{i, c, t}$ is the observed monthly log price change, and $e_{c, t-j+1}$ denotes TPC or USD movements. The figure shows the sum of the coefficients $\sum_{j=0}^{24} \beta_{j}$ estimated for each NAICS3 sector and exchange rate movement. For details of the construction of the exchange rate measures, see the discussion in the text. 
Table C.3: Long-Run Price Change Regressions

\begin{tabular}{l|ccc} 
& $(1)$ & $(2)$ & $(3)$ \\
\hline \hline$\rho$ & 10 & BW & 10 \\
& Competition at NAICS6 \\
\hline \multirow{2}{*}{ Predicted Price Changes } & 0.298 & 0.235 & 0.271 \\
& $(0.114)$ & $(0.121)$ & $(0.155)$ \\
Differentiated Goods? & - & - & Yes \\
\hline $\mathrm{N}$ & 6156 & 6156 & 2656 \\
$R^{2}$ & $13.47 \%$ & $12.83 \%$ & $16.82 \%$ \\
\hline
\end{tabular}

The table shows estimates of long-run pass-through from the following specification: $\Delta p_{i}^{L R}=\alpha_{i}+\beta^{L R} \Delta \hat{p}_{i}^{L R}+\epsilon_{i}$ where $\Delta p_{i}^{L R}$ denotes the log price change over the entire life-time of a good, $\Delta \hat{p}_{i}^{L R}$ the corresponding predicted log price change and $\alpha_{i}$ good-level fixed effects. The table shows estimates $\beta^{L R}$ and their standard errors in brackets. 


\section{Swiss National Bank Working Papers published since 2004:}

2004-1 Samuel Reynard: Financial Market Participation and the Apparent Instability of Money Demand

2004-2 Urs W. Birchler and Diana Hancock: What Does the Yield on Subordinated Bank Debt Measure?

2005-1 Hasan Bakhshi, Hashmat Khan and Barbara Rudolf: The Phillips curve under state-dependent pricing

2005-2 Andreas M. Fischer: On the Inadequacy of Newswire Reports for Empirical Research on Foreign Exchange Interventions

2006-1 Andreas M. Fischer: Measuring Income Elasticity for Swiss Money Demand: What do the Cantons say about Financial Innovation?

2006-2 Charlotte Christiansen and Angelo Ranaldo: Realized Bond-Stock Correlation: Macroeconomic Announcement Effects

2006-3 Martin Brown and Christian Zehnder: Credit Reporting, Relationship Banking, and Loan Repayment

2006-4 Hansjörg Lehmann and Michael Manz: The Exposure of Swiss Banks to Macroeconomic Shocks - an Empirical Investigation

2006-5 Katrin Assenmacher-Wesche and Stefan Gerlach: Money Growth, Output Gaps and Inflation at Low and High Frequency: Spectral Estimates for Switzerland

2006-6 Marlene Amstad and Andreas M. Fischer: Time-Varying Pass-Through from Import Prices to Consumer Prices: Evidence from an Event Study with Real-Time Data

2006-7 Samuel Reynard: Money and the Great Disinflation

2006-8 Urs W. Birchler and Matteo Facchinetti: Can bank supervisors rely on market data? A critical assessment from a Swiss perspective

2006-9 Petra Gerlach-Kristen: A Two-Pillar Phillips Curve for Switzerland

2006-10 Kevin J. Fox and Mathias Zurlinden: On Understanding Sources of Growth and Output Gaps for Switzerland

2006-11 Angelo Ranaldo: Intraday Market Dynamics Around Public Information Arrivals

2007-1 Andreas M. Fischer, Gulzina Isakova and Ulan Termechikov: Do FX traders in Bishkek have similar perceptions to their London colleagues? Survey evidence of market practitioners' views 
2007-2 Ibrahim Chowdhury and Andreas Schabert: Federal Reserve Policy viewed through a Money Supply Lens

2007-3 Angelo Ranaldo: Segmentation and Time-of-Day Patterns in Foreign Exchange Markets

2007-4 Jürg M. Blum: Why ‘Basel II’ May Need a Leverage Ratio Restriction

2007-5 Samuel Reynard: Maintaining Low Inflation: Money, Interest Rates, and Policy Stance

2007-6 Rina Rosenblatt-Wisch: Loss Aversion in Aggregate Macroeconomic Time Series

2007-7 Martin Brown, Maria Rueda Maurer, Tamara Pak and Nurlanbek Tynaev: Banking Sector Reform and Interest Rates in Transition Economies: Bank-Level Evidence from Kyrgyzstan

2007-8 Hans-Jürg Büttler: An Orthogonal Polynomial Approach to Estimate the Term Structure of Interest Rates

2007-9 Raphael Auer: The Colonial Origins Of Comparative Development: Comment. A Solution to the Settler Mortality Debate

2007-10 Franziska Bignasca and Enzo Rossi: Applying the Hirose-Kamada filter to Swiss data: Output gap and exchange rate pass-through estimates

2007-11 Angelo Ranaldo and Enzo Rossi: The reaction of asset markets to Swiss National Bank communication

2007-12 Lukas Burkhard and Andreas M. Fischer: Communicating Policy Options at the Zero Bound

2007-13 Katrin Assenmacher-Wesche, Stefan Gerlach, and Toshitaka Sekine: Monetary Factors and Inflation in Japan

2007-14 Jean-Marc Natal and Nicolas Stoffels: Globalization, markups and the natural rate of interest

2007-15 Martin Brown, Tullio Jappelli and Marco Pagano: Information Sharing and Credit: Firm-Level Evidence from Transition Countries

2007-16 Andreas M. Fischer, Matthias Lutz and Manuel Wälti: Who Prices Locally? Survey Evidence of Swiss Exporters

2007-17 Angelo Ranaldo and Paul Söderlind: Safe Haven Currencies 
2008-1 Martin Brown and Christian Zehnder: The Emergence of Information Sharing in Credit Markets

2008-2 Yvan Lengwiler and Carlos Lenz: Intelligible Factors for the Yield Curve

2008-3 Katrin Assenmacher-Wesche and M. Hashem Pesaran: Forecasting the Swiss Economy Using VECX* Models: An Exercise in Forecast Combination Across Models and Observation Windows

2008-4 Maria Clara Rueda Maurer: Foreign bank entry, institutional development and credit access: firm-level evidence from 22 transition countries

2008-5 Marlene Amstad and Andreas M. Fischer: Are Weekly Inflation Forecasts Informative?

2008-6 Raphael Auer and Thomas Chaney: Cost Pass Through in a Competitive Model of Pricing-to-Market

2008-7 Martin Brown, Armin Falk and Ernst Fehr: Competition and Relational Contracts: The Role of Unemployment as a Disciplinary Device

2008-8 Raphael Auer: The Colonial and Geographic Origins of Comparative Development

2008-9 Andreas M. Fischer and Angelo Ranaldo: Does FOMC News Increase Global FX Trading?

2008-10 Charlotte Christiansen and Angelo Ranaldo: Extreme Coexceedances in New EU Member States' Stock Markets

2008-11 Barbara Rudolf and Mathias Zurlinden: Measuring capital stocks and capital services in Switzerland

2008-12 Philip Sauré: How to Use Industrial Policy to Sustain Trade Agreements

2008-13 Thomas Bolli and Mathias Zurlinden: Measuring growth of labour quality and the quality-adjusted unemployment rate in Switzerland

2008-14 Samuel Reynard: What Drives the Swiss Franc?

2008-15 Daniel Kaufmann: Price-Setting Behaviour in Switzerland - Evidence from CPI Micro Data

2008-16 Katrin Assenmacher-Wesche and Stefan Gerlach: Financial Structure and the Impact of Monetary Policy on Asset Prices

2008-17 Ernst Fehr, Martin Brown and Christian Zehnder: On Reputation: A Microfoundation of Contract Enforcement and Price Rigidity 
2008-18 Raphael Auer and Andreas M. Fischer: The Effect of Low-Wage Import Competition on U.S. Inflationary Pressure

2008-19 Christian Beer, Steven Ongena and Marcel Peter: Borrowing in Foreign Currency: Austrian Households as Carry Traders

2009-1 Thomas Bolli and Mathias Zurlinden: Measurement of labor quality growth caused by unobservable characteristics

2009-2 Martin Brown, Steven Ongena and Pinar Yeșin: Foreign Currency Borrowing by Small Firms

2009-3 Matteo Bonato, Massimiliano Caporin and Angelo Ranaldo: Forecasting realized (co)variances with a block structure Wishart autoregressive model

2009-4 Paul Söderlind: Inflation Risk Premia and Survey Evidence on Macroeconomic Uncertainty

2009-5 Christian Hott: Explaining House Price Fluctuations

2009-6 Sarah M. Lein and Eva Köberl: Capacity Utilisation, Constraints and Price Adjustments under the Microscope

2009-7 Philipp Haene and Andy Sturm: Optimal Central Counterparty Risk Management

2009-8 Christian Hott: Banks and Real Estate Prices

2009-9 Terhi Jokipii and Alistair Milne: Bank Capital Buffer and Risk Adjustment Decisions

2009-10 Philip Sauré: Bounded Love of Variety and Patterns of Trade

2009-11 Nicole Allenspach: Banking and Transparency: Is More Information Always Better?

2009-12 Philip Sauré and Hosny Zoabi: Effects of Trade on Female Labor Force Participation

2009-13 Barbara Rudolf and Mathias Zurlinden: Productivity and economic growth in Switzerland 1991-2005

2009-14 Sébastien Kraenzlin and Martin Schlegel: Bidding Behavior in the SNB's Repo Auctions

2009-15 Martin Schlegel and Sébastien Kraenzlin: Demand for Reserves and the Central Bank's Management of Interest Rates

2009-16 Carlos Lenz and Marcel Savioz: Monetary determinants of the Swiss franc 
2010-1 Charlotte Christiansen, Angelo Ranaldo and Paul Söderlind: The Time-Varying Systematic Risk of Carry Trade Strategies

2010-2 Daniel Kaufmann: The Timing of Price Changes and the Role of Heterogeneity

2010-3 Loriano Mancini, Angelo Ranaldo and Jan Wrampelmeyer: Liquidity in the Foreign Exchange Market: Measurement, Commonality, and Risk Premiums

2010-4 Samuel Reynard and Andreas Schabert: Modeling Monetary Policy

2010-5 Pierre Monnin and Terhi Jokipii: The Impact of Banking Sector Stability on the Real Economy

2010-6 Sébastien Kraenzlin and Thomas Nellen: Daytime is money

2010-7 Philip Sauré: Overreporting Oil Reserves

2010-8 Elizabeth Steiner: Estimating a stock-flow model for the Swiss housing market

2010-9 Martin Brown, Steven Ongena, Alexander Popov, and Pinar Yeșin: Who Needs Credit and Who Gets Credit in Eastern Europe?

2010-10 Jean-Pierre Danthine and André Kurmann: The Business Cycle Implications of Reciprocity in Labor Relations

2010-11 Thomas Nitschka: Momentum in stock market returns: Implications for risk premia on foreign currencies

2010-12 Petra Gerlach-Kristen and Barbara Rudolf: Macroeconomic and interest rate volatility under alternative monetary operating procedures

2010-13 Raphael Auer: Consumer Heterogeneity and the Impact of Trade Liberalization: How Representative is the Representative Agent Framework?

2010-14 Tommaso Mancini Griffoli and Angelo Ranaldo: Limits to arbitrage during the crisis: funding liquidity constraints and covered interest parity

2010-15 Jean-Marc Natal: Monetary Policy Response to Oil Price Shocks

2010-16 Kathrin Degen and Andreas M. Fischer: Immigration and Swiss House Prices

2010-17 Andreas M. Fischer: Immigration and large banknotes

2010-18 Raphael Auer: Are Imports from Rich Nations Deskilling Emerging Economies? Human Capital and the Dynamic Effects of Trade 
2010-19 Jean-Pierre Danthine and John B. Donaldson: Executive Compensation: A General Equilibrium Perspective

2011-1 Thorsten Beck and Martin Brown: Which Households Use Banks? Evidence from the Transition Economies

2011-2 Martin Brown, Karolin Kirschenmann and Steven Ongena: Foreign Currency Loans Demand or Supply Driven?

2011-3 Victoria Galsband and Thomas Nitschka: Foreign currency returns and systematic risks

2011-4 Francis Breedon and Angelo Ranaldo: Intraday patterns in FX returns and order flow

2011-5 Basil Guggenheim, Sébastien Kraenzlin and Silvio Schumacher: Exploring an uncharted market: Evidence on the unsecured Swiss franc money market

2011-6 Pamela Hall: Is there any evidence of a Greenspan put?

2011-7 Daniel Kaufmann and Sarah Lein: Sectoral Inflation Dynamics, Idiosyncratic Shocks and Monetary Policy

2011-8 Iva Cecchin: Mortgage Rate Pass-Through in Switzerland

2011-9 Raphael A. Auer, Kathrin Degen and Andreas M. Fischer: Low-Wage Import Competition, Inflationary Pressure, and Industry Dynamics in Europe

2011-10 Raphael A. Auer and Philip Sauré: Spatial Competition in Quality, Demand-Induced Innovation, and Schumpeterian Growth

2011-11 Massimiliano Caporin , Angelo Ranaldo and Paolo Santucci de Magistris: On the Predictability of Stock Prices: a Case for High and Low Prices

2011-12 Jürg Mägerle and Thomas Nellen: Interoperability between central counterparties

2011-13 Sylvia Kaufmann: K-state switching models with endogenous transition distributions

2011-14 Sébastien Kraenzlin and Benedikt von Scarpatetti: Bargaining Power in the Repo Market

2012-01 Raphael A. Auer: Exchange Rate Pass-Through, Domestic Competition, and Inflation: Evidence from the 2005/08 Revaluation of the Renminbi

2012-02 Signe Krogstrup, Samuel Reynard and Barbara Sutter: Liquidity Effects of Quantitative Easing on Long-Term Interest Rates 
2012-03 Matteo Bonato, Massimiliano Caporin and Angelo Ranaldo: Risk spillovers in international equity portfolios

2012-04 Thomas Nitschka: Banking sectors' international interconnectedness: Implications for consumption risk sharing in Europe

2012-05 Martin Brown, Steven Ongena and Pinar Yeșin: Information Asymmetry and Foreign Currency Borrowing by Small Firms

2012-06 Philip Sauré and Hosny Zoabi: Retirement Age across Countries: The Role of Occupations

2012-07 Christian Hott and Terhi Jokipii: Housing Bubbles and Interest Rates

2012-08 Romain Baeriswyl and Camille Cornand: Reducing overreaction to central bank's disclosures: theory and experiment

2012-09 Bo E. Honoré, Daniel Kaufmann and Sarah Lein: Asymmetries in Price-Setting Behavior: New Microeconometric Evidence from Switzerland

2012-10 Thomas Nitschka: Global and country-specific business cycle risk in time-varying excess returns on asset markets

2012-11 Raphael A. Auer, Thomas Chaney and Philip Sauré: Quality Pricing-to-Market

2012-12 Sébastien Kraenzlin and Thomas Nellen: Access policy and money market segmentation

2012-13 Andreas Kropf and Philip Sauré: Fixed Costs per Shipment

2012-14 Raphael A. Auer and Raphael S. Schoenle: Market Structure and Exchange Rate Pass-Through 
Swiss National Bank Working Papers are also available at www.snb.ch, section Publications/Research Subscriptions or individual issues can be ordered at Swiss National Bank, Fraumünsterstrasse 8, CH-8022 Zurich, fax+41 4463181 14, E-mail library@snb.ch 